\title{
Suzuki-Miyaura micellar one pot synthesis of symmetrical and unsymmetrical 4,7-Diaryl-5,6-difluoro-2,1,3-benzothiadiazole luminescent derivatives in water and under air
}

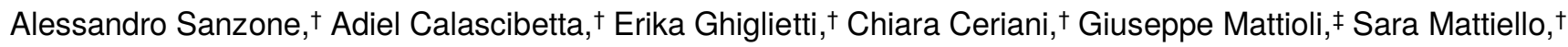
Mauro Sassi, ${ }^{\dagger}$ Luca Beverina ${ }^{\star}$

† Department of Materials Science, University of Milano-Bicocca, Via R. Cozzi, 55, Milano, Italy. I-20127

‡ CNR - ISTITUTO DI STRUTTURA DELLA MATERIA, Via Salaria Km 29,300 - C.P. 10 I-00015 - Monterotondo Scalo (RM)

ABSTRACT: The Suzuki-Miyaura cross coupling reaction of 4,7-dibromo-5,6-difluoro-2,1,3-benzothiadiazole (DBBF) with different arylboronic acids can be efficiently carried out in water and under air by means of micellar coupling. The careful tuning of reaction conditions enables preparation of symmetrically and unsymmetrically substituted derivatives. The moderate to good yields obtained, alongside with the wide variety of available substitution patterns, makes this sustainable methodology very resourceful for the preparation of building blocks for luminescent optoelectronic materials.

Graphical abstract<smiles>Fc1c(Br)c(Br)c2nsnc2c1Br</smiles>

Surfactant

Kolliphor EL

Kolliphor EL/Tween 80 (7:3)

Kolliphor EL/Span 80 (7:3)

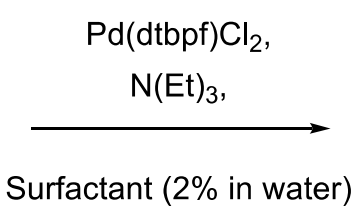

2 h r.t.

Yield

in air

$68 \%$

$75 \%$

$97 \%$<smiles>Fc1c(F)c(-c2cccs2)c2nsnc2c1-c1cccs1</smiles>

DTBT

(purification included)

\section{INTRODUCTION}

Organic (opto)electronics has played a major role in academic and industrial research in the last 30 years. OLEDs have already evolved into a strong market reality. The other 2 notable members of organic electronics' "big three”, i.e. photovoltaics (PV) and thin-film field effect transistors (TFTs), are expected to follow in the near future. ${ }^{1}$ When moving from the Lab to the Fab environment, high performance is not enough to ensure successful technology transfer. ${ }^{2}$ Active materials have to become available at the large scale and through sustainable processes. All hazards have to 
be minimized thus leaving little room for toxic and/or flammable solvents. ${ }^{3}$ Current state of the art printable materials are far from optimal in this respect. ${ }^{4}$ The processes leading to their synthesis are expensive and do not take into account established sustainability indexes like the $\mathrm{E}$ factor ( $\mathrm{kg}$ of organic waste and byproducts/kg of product). ${ }^{5}$ The class of the 4,7-diaryl-5,6-difluoro-2,1,3-benzothiadiazole derivatives, with 4,7-di(thiophene-2-yl)-5,6-difluoro-2,1,3benzothiadiazole (DTBT) as the most prominent member, is a representative example of such situation. DTBT (Scheme 1) is a commercially available, rather expensive, building block that is gaining a relevant momentum in the dedicated literature. ${ }^{6-9}$ In the last 8 years DTBT was reported, directly as it is or as a part of more complex polymer or molecule, in nearly 300 papers, with a steady increase in the number of hits per year (See Figure S1 of the ESI).

\section{Scheme 1. Literature vs micellar approach for the preparation of DTBT}

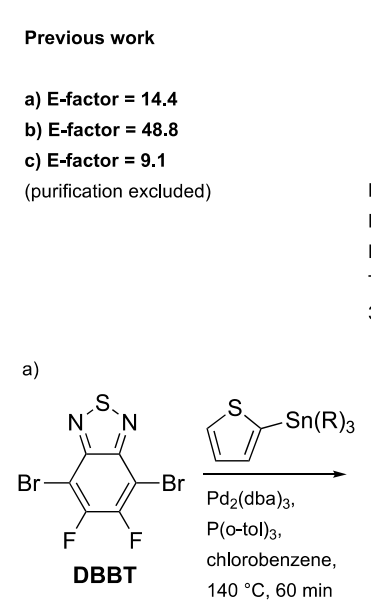

$95 \%$
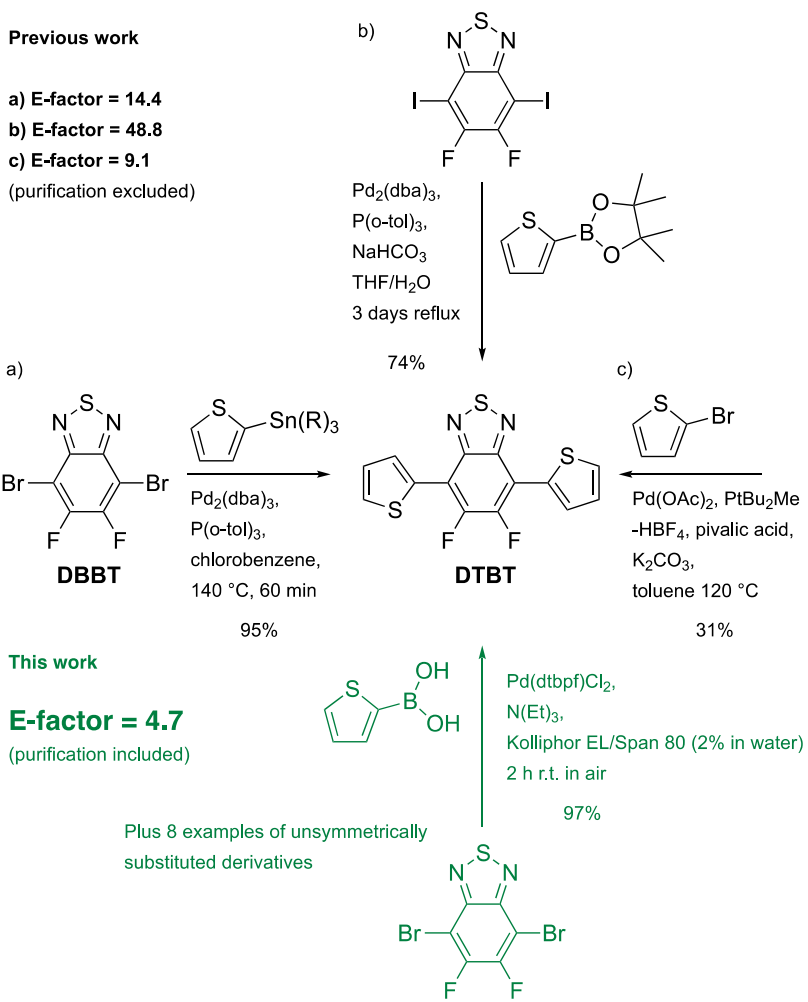

As shown in Scheme 1, DTBT can be prepared according to three routes: a) from 4,7-dibromo-5,6-difluoro-2,1,3benzothiadiazole (DBBF) and 2-tributylstannyl thiophene with various Stille coupling protocols, ${ }^{10,11}$ for example in chlorobenzene and under microwave irradiation ${ }^{8}$ b) from 4,7-diiodo-5,6-difluoro-2,1,3-benzothiadiazole and 2thienylboronic acid pinacol ester via Suzuki-Miyaura (SM) coupling in water/THF mixture in moderate to good yield; ${ }^{12} \mathrm{c}$ ) directly from 5,6-difluoro-2,1,3-benzothiadiazole and 2-bromothiophene via C-H activation, in modest yield. ${ }^{13}$ None of such methods can be considered sustainable. The Stille route is efficient but involves both the use of organic solvents and of tin compounds. The Suzuki coupling is generally inefficient in the case of thiophene containing derivatives as the poor reactivity of the thienyl-boronic acid is connected with a pronounced tendency to protodeborylation, particularly at high temperature. ${ }^{14}$ Finally, the $\mathrm{C}-\mathrm{H}$ activation is attractive, as it does not require activation of 5,6 -difluoro-2,1,3benzothiadiazole (DFBT), allowing easy access to several symmetrically and unsymmetrically substituted derivatives. 
However, its generality is limited to substrates having $\mathrm{C}-\mathrm{H}$ reactivities lower than those of DFBT and the intermediate in order to retain chemoselectivity and high yields, as testified by literature results with bromothiophene (low product yields and olygothiophenes formation $)^{13}$.

Micellar synthesis has demonstrated strong potential to improve sustainability. ${ }^{15-17}$ Micellar reactions are a wellestablished topic in modern organic synthesis. ${ }^{18-23}$ They enable the use of well-known $\mathrm{C}-\mathrm{C}$ and $\mathrm{C}-\mathrm{N}$ bond-forming strategies in water and frequently at room temperature, with ample recyclability of the reaction medium. ${ }^{24-36}$ Recently, a relevant example of a photoredox transformation in micellar environment was also reported. ${ }^{25}$ The use of such methods in the field of organic semiconductors is still limited and only a few examples of relevant conjugated molecular materials are reported. ${ }^{5,37-40}$

Here we show that the careful tuning of reaction conditions - in this case particularly referring to the definition of the micellar environment through a formulation chemistry approach - enables the preparation in quantitative yield of DTBT in water as the only solvent, at room temperature and under standard laboratory environment by means of the SM coupling of DBBF and 2-thienylboronic acid. We also show that conditions can be tuned in order to prepare unsymmetrical derivatives bearing two different aryl residues in a one pot procedure not requiring the isolation of the monoarylated intermediate.

Results are relevant both as they provide a simple and sustainable access to valuable intermediates and because they shed some light on the peculiar characteristic of micro-heterogeneous micellar reactions over homogeneous phase approaches.

\section{RESULTS AND DISCUSSION}

\section{Micellar synthesis of DTBT.}

We recently prepared the two 4,7-diaryl-2,1,3-benzothiadiazole derivatives shown in Scheme $2 a$ by means of an efficient room temperature micellar SM reaction, carried out in a 2 wt\% water solution of the industrial surfactant Kolliphor EL. ${ }^{40}$ Whilst the phenyl end-capped derivative 1 can be prepared in quantitative yield using $2 \mathrm{~mol} \% \mathrm{Pd}(\mathrm{dppf}) \mathrm{Cl} 2$ as the catalysts, the synthesis of 2 requires the use of the more efficient $\mathrm{Pd}(\mathrm{dtbpf}) \mathrm{Cl}_{2}$ in analogous stoichiometry. No doubt, this is connected with the poor reactivity of 2-thienylboronic acid. However, in both reactions we did not observe the formation of the monoarylated species. Reactions where selective towards the formation of the diarylated compounds, even in the case of excess of 4,7-dibromo-2,1,3-benzothiadiazole over the boronic acid employed (Scheme 2a).

The aforementioned syntheses could also be carried out in other popular designer surfactants such as TPGS-750-M with similar efficiency. However, the use of Kolliphor EL was found to be advantageous as the reaction could be carried out with identical results irrespective to the atmosphere employed. We routinely carried out reactions in standard test tubes, under normal laboratory environment. As this feature is advantageous in both speeding up laboratory practices and improving the overall sustainability of scaled up processes, we decided to further investigate the applicability of 
Kolliphor EL and structurally related commercially available surfactants in the preparation of other relevant molecular materials and precursors.

Unfortunately, when moving from 4,7-dibromo-2,1,3-benzothiadiazole to the more optoelectronic applications relevant DBBF, the reaction behaviour changes completely. As it is shown in Scheme $2 b$, the reaction carried out with $\mathrm{Pd}(\mathrm{dppf}) \mathrm{Cl} 2$ gives very little conversion, mostly leading to the monoarylated species. The only byproducts we observed by GC-MS of the reaction mixture were bithiophene (the homocoupling product of the boronic acid) and 4-(thiophene-2-yl)-5,6difluoro-2,1,3-benzothiadiazole, both of them in concentration below $0.5 \%$. TLC inspection and NMR analysis confirmed that the 2-thienylboronic acid was still present, so that protodeborylation can be ruled out as the reason for the reaction not reaching full conversion.

When switching to $\mathrm{Pd}(\mathrm{dtbpf}) \mathrm{Cl}_{2}$, the conversion increases substantially yet the reaction does not go to completion. Further extension of the reaction time does not influence the composition of the reaction mixture. As in the previous case, the homocoupling and debromination byproducts are barely distinguishable from the background noise in the GCMS traces (all traces are reported in the ESI).

Scheme 2. Difference in the mono vs diarylation selectivity in SM reactions carried out on 4,7-dibromo-2,1,3-benzothiadiazole vs DBBF.
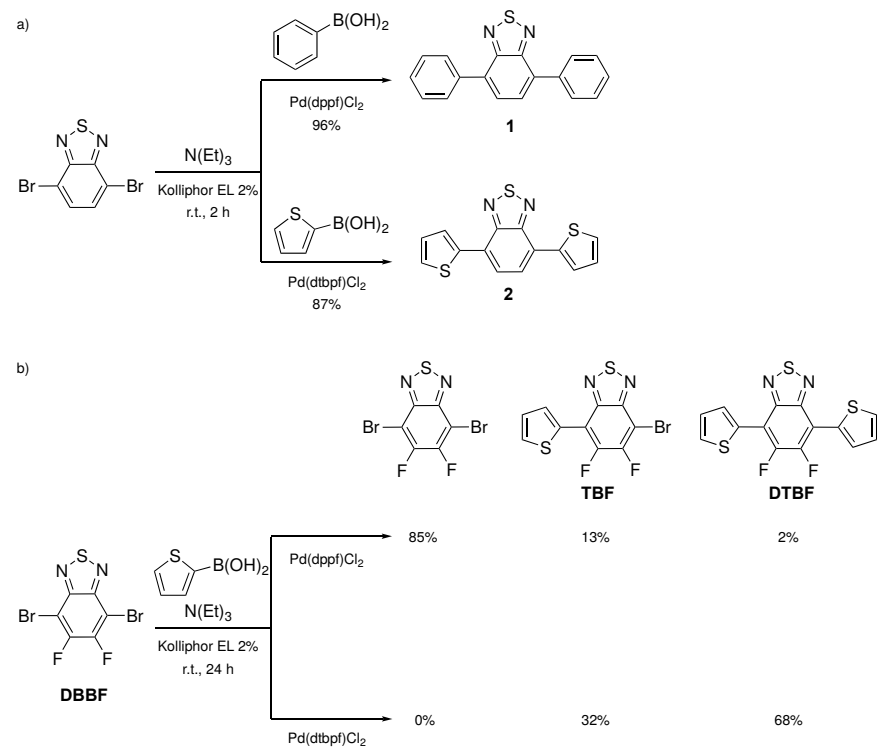

In order to evaluate the generality of the effect, we also tested the coupling of DBBF with two additional boronic acids: 3-thienylboronic acid and phenylboronic acid. Reactions were performed in 2 wt\% Kolliphor EL under standardized conditions: $0.5 \mathrm{M} \mathrm{DBBF}, 1.5 \mathrm{M}$ boronic acid, $3 \mathrm{M} \mathrm{N}(\mathrm{Et})_{3}$ and $2 \mathrm{~mol} \%$ with respect to the bromide of $\mathrm{Pd}(\mathrm{dppf}) \mathrm{Cl} 2 . \mathrm{Scheme}$ 3 shows the results we obtained. 
Scheme 3. Examples of SM reactions carried out on DBBF and leading to limited conversion.

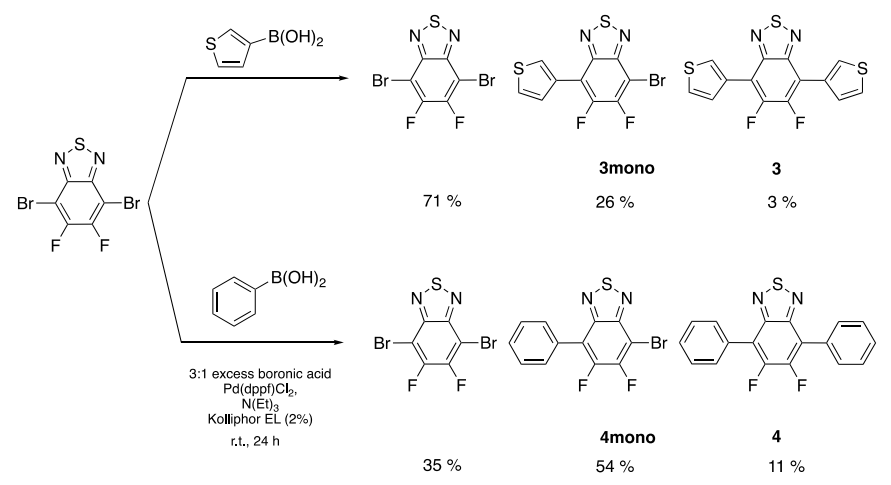

None of the reaction gave complete conversion and the monocoupling product was the dominating component. Results also reflect the different reactivity of the boronic acids employed: the reaction performed with phenylboronic acid was sizeably more effective. We recently observed a similar behaviour in the SM coupling of both thiophene and phenyl boronic acid with di-bromides pertaining to the family of the latent pigments. Such species give essentially no conversion with a variety of surfactants (including the popular designer surfactant TPGS-750-M ${ }^{41}$ ) and catalysts. The reaction becomes very efficient in the presence of a small amount of a water immiscible co-solvent of suitable polarity. ${ }^{39}$ Such observation hinted at a problem of lack of efficient dispersion of the reactive species within the reaction mixture, thus requiring evolution from micellar to an emulsion approach. Indeed, micellar reaction have recently been considered somewhat capricious as sight difference in the experimental conditions can lead to sizeably different outputs. ${ }^{42}$ The use of a co-solvent is a known and resourceful tool. ${ }^{43,44}$ Although efficient, it remains unsatisfactory from the stand point of sustainability and E-factor reduction, as the use of organic solvents should be limited as much as possible.

In the present paper we aim both at finding a satisfactory protocol leading to DTBT in high yield and without the use of organic solvents and at the elucidation of the factors limiting the conversion in Scheme 2 and 3 reactions. We thus decided to use the SM coupling of DBBF and 2-thienylboronic acid as a relevant case study and we evaluated the product distribution as a function of key reaction parameters: the concentration and nature of the surfactant(s), the concentration of the reagents, and the nature of the catalyst. The computationally aided rationalization of the results was finally exploited for the identification of conditions preferentially giving mono vs double SM coupling in order to prepare unsymmetrically substituted derivatives in a one pot procedure.

\section{Influence of the surfactant concentration.}

The first parameter we investigated was the concentration of the surfactant. Literature data mostly refer to a 2 wt $\%$ as the best trade-off between efficiency and cost. The latter factor is not that relevant in the case of Kolliphor EL, we thus examined 2, 5, 10 and 20 wt\% solutions. The DLS analysis of the surfactant solution (see figure S2) shows that while there is little difference between 2, 5 and 10 wt\% solutions in terms of the dimensions of the micelles obtained, the 20 wt\% one also contains aggregates of larger dimensions. We carried out all reactions under standardized conditions: 0.5 $\mathrm{M}$ DBBF, $1.5 \mathrm{M}$ 2-thienylboronic acid, $3 \mathrm{M} \mathrm{N}(\mathrm{Et})_{3}$ and 2 mol\% with respect to the bromide of $\mathrm{Pd}(\mathrm{dppf}) \mathrm{Cl} \mathrm{l}_{2}$. Initially, we 
purposefully decided to use $\mathrm{Pd}(\mathrm{dppf}) \mathrm{Cl}_{2}$ over the more reactive $\mathrm{Pd}(\mathrm{dtbpf}) \mathrm{Cl}_{2}$ in order to magnify the differences between the various reaction conditions employed. All reactions were quenched after $12 \mathrm{~h}$ stirring at room temperature, extracted with $\mathrm{CH}_{2} \mathrm{Cl}_{2}$, filtered over a pad of silica gel and submitted to GC-MS characterization. Table 1 shows the product distributions we obtained. All values are corrected for the instrument response factor for the three different analytes, they thus correspond to the GC-MS yields of the different compounds (See Supporting Information for details).

Table 1. Influence of the Surfactant concentration in the SM coupling reaction between DBBF and 2-thienylboronic acid. Conditions: 0.5 M DBBF, 1.5 M 2-thienylboronic acid, $3 \mathrm{M} \mathrm{N}(\mathrm{Et})_{3}$ and $2 \mathrm{~mol} \%$ with respect to the bromide of $\mathrm{Pd}(\mathrm{dppf}) \mathrm{Cl}_{2}$. Room temperature

\begin{tabular}{ccccc}
\hline Entry & Surfactant concentration (wt\%) & DBBF (mol\%) & TBF (mol\%) & DTBT (mol\%) \\
\hline 1 & 2 & 85 & 13 & 2 \\
2 & 5 & 64 & 33 & 3 \\
3 & 10 & 28 & 65 & 7 \\
4 & 20 & 61 & 34 & 5
\end{tabular}

With the exclusion of the data relative to the $20 \mathrm{wt} \%$ solution - where in any case the mixture is out of the micellar regime as evidenced by the DLS data - the reaction becomes increasingly more efficient at higher surfactant concentration. The reaction is somewhat selective to the monoarylated product even in the presence of a large excess of boronic acid. Running the reaction for a longer time and/or under nitrogen atmosphere did not influence the conversion nor changed in any way the product distribution.

\section{Influence of the reagents formal concentration.}

At a fixed surfactant concentration of $2 \mathrm{wt} \%$, we varied the formal concentration of the reagents, while leaving fixed the respective stoichiometry ratio of 1:3:6:0.02 for DBBF:boronic acid:N(Et)3:catalyst respectively.

Table 2. Influence of the reagents molarity at 2 wt\% Kolliphor concentration in the SM coupling reaction between DBBF and 2thienylboronic acid. Reaction carried out at room temperature, $12 \mathrm{~h}$.

\begin{tabular}{ccccc}
\hline Entry & DBBF $[\mathrm{M}]$ & DBBF (mol\%) & TBF (mol\%) & DTBT (mol\%) \\
\hline 1 & 0.3 & 84 & 15 & 1 \\
2 & 0.5 & 85 & 13 & 2 \\
3 & 1.0 & 77 & 21 & 2 \\
4 & 1.5 & 92 & 8 & 0
\end{tabular}

It should be noted that in a micellar reaction most of the reagents and products are just suspended in water. As such, the nominal concentration may not be correlated with the stoichiometric ratio within the micelle and/or at the various interphases between reagents, water and micelles. Table 2 shows the results we obtained.

The reaction shows very little sensitivity to the concentration of the reagents. Within the $0.5-1.0 \mathrm{M}$ nominal concentration the reaction gives best results. It should be noted that at $1.0 \mathrm{M}$ concentration the reaction mixture is very viscous and mechanical stirring is recommended. 


\section{Influence of the Surfactant.}

Literature reports a large number of surfactants suitable to carry out SM coupling in high yield and at room temperature under micellar conditions. ${ }^{16}$ Some of them are well established industrial surfactants originally developed for the needs of formulation chemistry. ${ }^{20}$ Others specifically designed for micellar reactions have been shown to feature superior performances in terms of yield and/or reduction of the reaction time. ${ }^{32,41,45-47}$ Despite the seminal value of these observations, there are no general structure-property relationships clearly correlating performances in micellar reactions with the surfactant chemical nature. Mostly, the difference in performances are ascribed to the aspect ratio (spherical vs worm like) and/or dimensions of the micelles obtained in water solution. Recently, a seminal computational investigation of the association behaviour of micelles was also reported. ${ }^{48}$

In the case of underperforming reactions such as the couplings shown in Schemes $2 b$ and 3 , the use of specifically designed surfactants could be of help. Yet, from the standpoint of sustainability, the synthetic effort put in the preparation of the surfactant should be considered. Some designer surfactants are now commercially available, yet none of them is comparable, in terms of cost and sustainability, with the large number of industrial surfactants constituting the toolbox of the formulation chemist.

Moreover, the primary role of the surfactant in a SM micellar coupling is to provide a microenvironment where the reaction can take place. The task is somewhat similar to the preparation of stable emulsions: organic phase and surfactant characteristics need to be carefully matched in order to ensure durability. The production of a specific surfactant to suit the needs of every organics is unpractical and the use of mixtures is a routine practice.

Accordingly, the use of a mixture of existing and readily available surfactants, aimed at tuning the interaction of the micelles with either the reagents or the products of a given reaction, could be a very resourceful tool for micellar couplings as well.

Commercial surfactants are complex molecules possessing functional groups of different polarity. In the case of polyethoxylated species, like Kolliphor EL, they are also intrinsically polydisperse. In order to be able to qualitatively describe the affinity of a given surfactant with respect to a phase to be dispersed/emulsified, formulation chemists developed the concept of the Hydrophilic Lipophilic Balance (HLB). This is a completely empirical parameter, not necessarily linearly correlated for example with the dielectric constant, that gives a qualitative idea of the affinity of a surfactant for water (HLB>10) or for oil (HLB<10). ${ }^{49}$ The HLB of Kolliphor EL is 13.5, which identifies it as water soluble and appropriate for the preparation of oil in water emulsions. Aiming at tuning the interaction of Kolliphor EL with the components of the reaction mixture, we decided to mix it with two other neutral and polyethoxylated industrial surfactants, Tween 80 and Span 80, featuring an HLB of 15 and 4.3, respectively. In both cases we mixed the surfactants in a 7:3 ratio Kolliphor/co-surfactant. As it is discussed below, this proportion is dictated by the limited solubility in water of Span 80. The HLB values of the two mixtures can be calculated as the weighted average of the HLB of the pure constituents, thus the Kolliphor EL/Span 80 mixture has an HLB value of 10.7 and the Kolliphor EL/Tween 80 mixture of 14.0 . As we 
have previously stressed, the HLB cannot be directly related to the dielectric constant or the partition coefficient of the surfactants, yet it is safe to assume that at higher HLB values more polar derivatives will be preferentially dispersed.

Table 3 shows the results we obtained while running the reaction at a 2 wt\% surfactant concentration and at a nominal concentration of $0.5 \mathrm{M}$ for the bromide. The decision to work at $2 \mathrm{wt} \%$ was dictated by the very limited solubility of Span 80 in water.

Table 3. Influence of the Surfactants nature at 2 wt\% concentration in the SM coupling reaction between DBBF and 2-thienylboronic acid. Conditions: $0.5 \mathrm{M} \mathrm{DBBF}, 1.5 \mathrm{M}$ 2-thienylboronic acid, $3 \mathrm{M} \mathrm{N}(\mathrm{Et})_{3}$ and $2 \mathrm{~mol} \%$ with respect to the bromide of $\mathrm{Pd}(\mathrm{dppf}) \mathrm{Cl}_{2}$.

\begin{tabular}{|c|c|c|c|c|}
\hline Entry & Surfactant (HLB) & DBBF (mol \%) & TBF (mol \%) & DTBT $(\mathrm{mol} \%)$ \\
\hline 1 & Kolliphor EL (13.5) & 85 & 13 & 2 \\
\hline 2 & 70\% Kolliphor EL 30\% Span 80 (10.7) & 76 & 22 & 2 \\
\hline 3 & 70\% Kolliphor EL 30\% Tween 80 (14.0) & 95 & 5 & 0 \\
\hline
\end{tabular}

The conversion degree is poor in all three cases, yet sizeably improving when working at low HLB values. In principle, it could be interesting to explore even lower HLB values, yet this is technically difficult as surfactants approaching an HLB value of 10 are perfectly balanced between lipophilic and hydrophilic behaviour and are only partially soluble in water. Span 80 in particular is not water soluble and can be homogeneously dispersed in water only in the employed 7:3 mixture with Kolliphor EL and even then, requiring the use of a high shear mixer. Simple stirring does not provide a homogeneous formulation.

It should be stressed that even in the case of surfactants mixtures, all reactions were carried out under standard laboratory environment as no variation whatsoever in the product distribution and/or conversion degree was observed when working under nitrogen atmosphere.

\section{Influence of the catalyst.}

Having assessed that the reaction is favoured by higher surfactant concentration and, at least to some extent by lower HLB values, we tested under selected formulation conditions the use of the way more reactive catalysts $\mathrm{Pd}(\mathrm{dtbpf}) \mathrm{Cl}_{2}$ instead of $\mathrm{Pd}(\mathrm{dppf}) \mathrm{Cl}_{2}{ }^{50,51}$. Table 4 shows the results. 
Table 4. Influence of the catalyst as the function of reaction formulation in the SM coupling reaction between DBBF and 2-thienylboronic acid. Conditions: $0.5 \mathrm{M} \mathrm{DBBF}, 1.5 \mathrm{M}$ 2-thienylboronic acid, $3 \mathrm{M} \mathrm{N}(\mathrm{Et})_{3}$ and $2 \mathrm{~mol} \%$ with respect to the bromide of the catalyst. Room temperature, $12 \mathrm{~h}$.

\begin{tabular}{cccccc}
\hline Entry & Surfactant & Catalyst & DBBF & TBF & DTBT \\
\hline 1 & Kolliphor EL & $\mathrm{Pd}(\mathrm{dppf}) \mathrm{Cl}_{2}$ & 85 & 13 & 2 \\
2 & Kolliphor EL & $\mathrm{Pd}(\mathrm{dtbpf}) \mathrm{Cl}_{2}$ & 0 & 32 & 68 \\
3 & $70 \%$ Kolliphor EL 30\% Span 80 & $\mathrm{Pd}(\mathrm{dppf}) \mathrm{Cl}_{2}$ & 76 & 22 & 2 \\
4 & $70 \%$ Kolliphor EL 30\% Span 80 & $\mathrm{Pd}(\mathrm{dtbpf}) \mathrm{Cl}_{2}$ & 0 & 3 & 97 \\
5 & $70 \%$ Kolliphor EL 30\% Tween 80 & $\mathrm{Pd}(\mathrm{dppf}) \mathrm{Cl}_{2}$ & 95 & 5 & 0 \\
6 & $70 \%$ Kolliphor EL 30\% Tween 80 & $\mathrm{Pd}(\mathrm{dtbpf}) \mathrm{Cl}_{2}$ & 0 & 25 & 75 \\
7 & $70 \%$ Kolliphor EL 30\% Span 80a & $\mathrm{Pd}(\mathrm{dtbpf}) \mathrm{Cl}_{2}$ & 0 & 75 & 25 \\
8 & $70 \%$ Kolliphor EL 30\% Tween 80 & $\mathrm{Pd}(\mathrm{dtbpf}) \mathrm{Cl}_{2}$ & 0 & 83 & 17 \\
9 & $70 \%$ Kolliphor EL 30\% Span 80 & $\mathrm{Pd}(\mathrm{dtbpf}) \mathrm{Cl}_{2}$ & 48 & 44 & 8 \\
\hline
\end{tabular}

a Reaction conditions: $0.5 \mathrm{M}$ DBBF, $0.75 \mathrm{M}$ 2-thienylboronic acid, $1.5 \mathrm{M} \mathrm{N}(\mathrm{Et})_{3}$ and $2 \mathrm{~mol} \%$ with respect to the bromide of $\mathrm{Pd}(\mathrm{dtbpf}) \mathrm{Cl}_{2 .}{ }^{\mathrm{b}}$ Conditions: $0.5 \mathrm{M} \mathrm{DBBF}, 1.5 \mathrm{M}$ 2-thienylboronic acid, $3 \mathrm{M} \mathrm{N}(\mathrm{Et})_{3}$ and 0.05 mol\% with respect to the bromide of the catalyst. Room temperature, $12 \mathrm{~h}$.

The use of $\mathrm{Pd}(\mathrm{dtbpf}) \mathrm{Cl}_{2}$ greatly improves the conversion under all conditions explored, we however managed to push reaction to completion, with nearly quantitative formation of the diarylation product, only in the case of the Kolliphor EL/Span 80 mixture, corresponding to the lowest HLB mixture we explored. The mono Vs diarylation ratio can be controlled by tuning the stoichiometry of the 2-thienylboronic acid. Entry 8 of Table 4, corresponding to a reaction where the boronic acid was used in 1.5 to 1 stoichiometric ratio over DBBF instead of the larger excess of 3:1 we employed in all other trials, shows that is it possible to prepare the monoarylated species at $83 \%$ yield without appreciable unreacted DBBF and in the presence of only $17 \%$ of DTBT. As it is discussed below, this result opens the way to the preparation of unsymmetrical derivatives.

\section{Computational analysis.}


The datasets described in Table 1-4 demonstrates that the nature of the micro heterogeneous environment where reactions take place has a strong influence on the product distributions and overall conversion. It remains however an open question the reason why reactions performed on 4,7-dibromo-2,1,3-benzothiadiazole are selective towards double SM coupling whilst the opposite is true for DBBF. We carried out a computational analysis of the various aryl halides and corresponding products of mono- and di-arylation in order to get relevant parameters, mostly the dipole moment, to be used as a guide in the elucidation of surfactant/molecules interaction within the micelles. A quantitative correlation of the dipole moment of the chemical species involved and the HLB of the surfactant(s) employed would be an overstretching of an empirical parameter introduced to describe the stability of industrial formulations. Nonetheless the comparison of the calculated dipole moments in water and toluene of DBBF, 4,7-dibromo-2,1,3-benzothiadiazole and the corresponding mono and diarylation products with the various boronic acids we employed (Scheme 4) could offer relevant trends in the sign and magnitude of the polarity variation of the different species along the pathway going from reagents to products. In fact, as the capability of the surfactants we used to form stable colloidal dispersions with lyophobic species is correlated with respective polarities, changes in the dipole moments could offer a rational for reactions selectively leading to mono over diarylated products.

Scheme 4. Calculated dipole moments in toluene for 4,7-dibromo-2,1,3-benzothiadiazole, DBBF and the corresponding mono and diarylation products with 2-thienylboronic acid, 3-thienylboronic acid and phenylboronic acid. Values are averaged amongst the two (for monoarylation products) and three (for diarylation products) almost degenerate rotamers available (see ESI for details). 


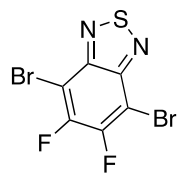

$1.14 \mathrm{D}$

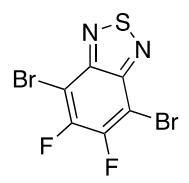

$1.14 \mathrm{D}$

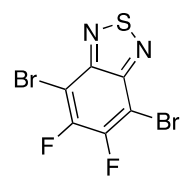

1.14 D

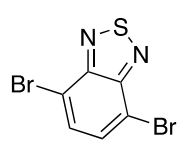

$1.54 \mathrm{D}$

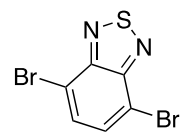

$1.54 \mathrm{D}$

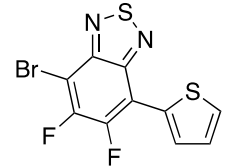

$2.84 \mathrm{D}$

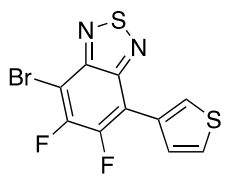

$2.23 \mathrm{D}$

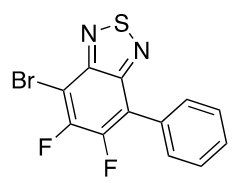

$2.51 \mathrm{D}$

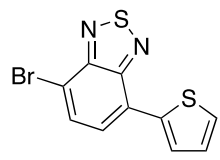

$3.06 \mathrm{D}$

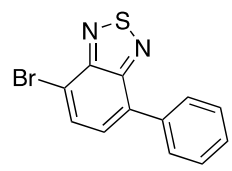

$2.93 \mathrm{D}$

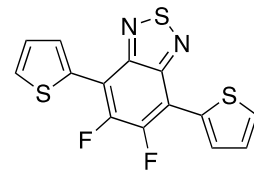

$1.05 \mathrm{D}$

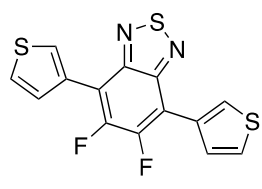

$0.92 \mathrm{D}$

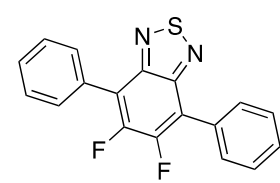

$0.88 \mathrm{D}$

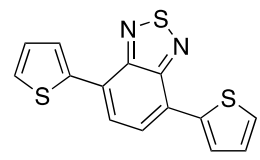

$1.45 \mathrm{D}$

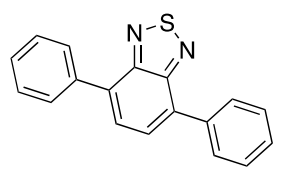

$1.90 \mathrm{D}$ 
We thus carried out a series of ab initio simulations based on density functional theory (DFT), performed by using the ORCA suite of programs. ${ }^{52}$ We report first that all the mono- and diarylated compounds are characterized by the occurrence of almost degenerate (energy difference never larger than $0.013 \mathrm{eV}$ ) stable rotamers. In 2- and 3-thienyl adducts, the solid angle between the DBBF (4,7-dibromo-2,1,3-benzothiadiazole) and thienyl planes generally approaches $0^{\circ}$ or $180^{\circ}$ values, corresponding to two nonequivalent isomers in the case of monoarylated compounds. Such isomers are characterized by similar molecular dipoles, always higher than that calculated for the unsubstituted DBBF and 4,7-dibromo-2,1,3-benzothiadiazole. The two equivalent monosubstituted phenyl rotamers (solid angle of $40^{\circ}$ ) are also characterized by a similar increase in the molecular dipole. Such increase is due to the strong component of the dipole moment rotated astray from the C2 symmetry axis of DBBF (4,7-dibromo-2,1,3-benzothiadiazole) in all monoarylated compounds. The addition of a second aryl group generally leads to the formation of three possible and again almost-degenerate isomers, and, in turn, to the symmetrisation of the molecule, with the dipole of monoarylated compounds counterbalanced by the presence of a second thienyl or phenyl group. The resultant dipole vector is far shorter in diarylated molecules than in monoarylated, and also shorter than that calculated for DBBF, while it is longer in the case of 4,7-dibromo-2,1,3-benzothiadiazole, having a dipole vector collinear but inverted with respect to DBBF. Without loss of generality, dipole values reported in Scheme 4 are averaged on rotational isomers; a detailed description of all the investigated isomers, including relative energies and interconversion barriers, has been reported in the ESI.

Even if the calculated values of the dipole moments in water and toluene are different, the same trend is reproduced in both datasets. Only derivatives $\mathbf{1}$ and $\mathbf{2}$ shows a polarity similar or higher than that of the starting dibromide. In all other cases, the diarylation product is sizeably less polar than both the starting bromide and the monoarylated intermediate.

The consequences of such findings will be discussed in the next session in the general interpretation of all the data (both experimental and computational) so far discussed.

\section{Discussion.}

Most micellar reactions described in the literature require the use of a 2 to 5 wt\% solution of surfactant in the presence of 0.5 to $1.0 \mathrm{M}$ solutions of the reagents. As it is also quite clear from the various pictures that can be found in the published papers (as well as in figure S3 of the Supporting Information), reaction vessels contain way more water insoluble material than the maximum amount that can be incorporated within the micelles at a given time. Actually, micellar synthesis is not a completely appropriate term as the reaction mixture is a suspension.

For all reactions giving no useful results in water alone (the so called reaction "on water" conditions, documented for SM couplings but lacking generality and in any case not working at all in the case of DTBT), achievement of complete conversion requires that a single micelle takes up reagents, localizes them in the same compartment where the catalyst is also present, assists to their transformation in the product and eventually releases the latter to replace it with a fresh aliquot of the former. This cycle has to be repeated several times, depending on the concentration of the surfactant. In the absence of a selective affinity for products vs reagents, within the normal uptake/release equilibria involving all 
micelles, products and reagents will have a probability of being incorporated that will depend on their relative concentration. The reaction will eventually slow down but go to complete conversion anyway. If, however the aryl halide and the corresponding arylation product have a sizeably different affinity for the micelle compartment where the reactions take place, one of the two will be preferentially incorporated. If micelles preferentially take up the halide, the reaction will be particularly efficient. On the opposite, in the case of preferential uptake of the product, the reaction will be severely slowed down by saturation of the active sites. The latter effect appears to be affecting the coupling of DBBF and 2thienylboronic acid. Indeed, the conversion degree depends linearly upon the amount of surfactant employed. The dependency of the mono vs diarylation ratio with the surfactant concentration is less pronounced. Within the experimental error connected with the small amount of DTBT obtained, the ratio can be assumed to be almost independent from the surfactant concentration. The data suggest that a saturation effect prevents the micelles from performing the coupling reactions multiple times, opposite to what is happening in the case of, for example, the preparation of $\mathbf{1}$ and $\mathbf{2}$.

To gain further evidence that reactions do not proceed above a certain conversion degree due to selective affinity towards the products, we carried out Scheme 5 reaction working at $0.5 \mathrm{M}$ nominal concentration of bromide in a 2 wt\% Kolliphor EL solution. We let the formulation equilibrate for $24 \mathrm{~h}$ under stirring, prior to add the catalyst and the base. The formation of the diarylated species was barely detectable. Actually, at least half of the DTBT detected by the GCMS after $24 \mathrm{~h}$ was already present at the beginning of the reaction as a contaminant of the monoarylated specie, whose chromatographic purification from DTBT is troublesome.

Scheme 5. SM reaction of TBF and 2-thienylboronic acid in 2 wt\% Kolliphor EL demonstrating the micelles saturation effect.

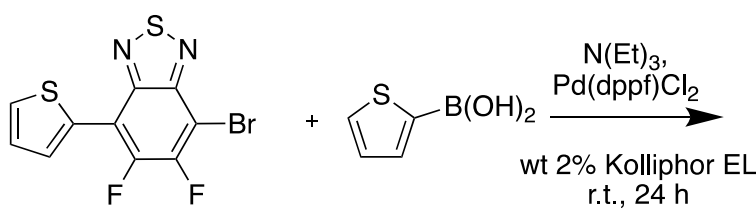

r.t., $24 \mathrm{~h}$

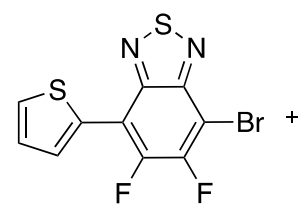

$98 \%$

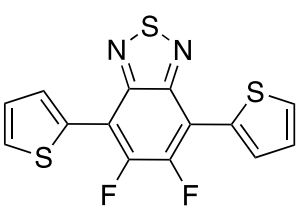

$2 \%$

It is accepted that in a micellar protocol, chemical transformations happen preferentially within the apolar core, where the catalyst is localized (this is in particular demonstrated in the case of Kolliphor EL according to our previous experience). ${ }^{40}$ The computational results summarized in Scheme 4 differentiate fluorinated from nonfluorinated derivatives on the basis of the polarity of both precursors and reagents. In both cases the polarity is increased by the first coupling and decreased by the second one, essentially due to geometrical reasons. Fluorinated derivatives remain however in all of the cases less polar than the nonfluorinated ones.

When we carried out reactions in Kolliphor EL, at the relatively high HLB values of 13.5, we privileged the emulsification of polar over nonpolar substances. In the nonfluorinated series, likewise generally better matched with Kolliphor EL HLB, dibromide and diarylated derivatives possess similar and relatively high polarity. The micelles do not preferentially stabilize neither of them and the reaction goes to completion. The most polar species, the monoarylated intermediate, 
is never observed as it reacts directly prior to leave the micelle. In the fluorinated series the polarity of all involved species is smaller so that the emulsification of DBBF in the first place is sluggish (indeed even by eye inspection it takes several minutes to observe the formation of a homogeneous dispersion). Moreover, reaction leads to a further reduction of polarity on going from DBBF to the diarylated species. At high HLB values the reaction does not perform for lack of compatibility. At low HLB values the situation improves yet the conversion remains limited by the preferential accumulation of diarylation product (the less polar species) over reagent within the micelles. Due to the aforementioned slow homogenization of the reaction mixture, the saturation effect takes some time to happen. When $\mathrm{Pd}(\mathrm{dppf}) \mathrm{Cl}_{2}$ is $u$ sed the reaction is very slow and the micelles saturation effect is dominating over conversion. The opposite is true when $\mathrm{Pd}(\mathrm{dtbpf}) \mathrm{Cl}_{2}$ is used, the reaction is very fast (GC-MS traces after 30 min and $12 \mathrm{~h}$ are identical) and proceeds smoothly, in the low HLB mixture (Table 4 entry 4) and somewhat less performantly at higher HLB factors (Table 4, Entries 2 and 6). Interestingly, at catalyst loading of $0.05 \mathrm{~mol} \%$, when the reaction is in any case slow, even with $\mathrm{Pd}(\mathrm{dtbpf}) \mathrm{Cl}_{2}$ and in the low HLB surfactant mixture, we obtained results fully comparable with those obtained with $\mathrm{Pd}(\mathrm{dppf}) \mathrm{Cl}_{2}(\mathrm{Table} 4$, entry 9).

Entry 4 of Table 4 shows that the use of 2 mol\% of $\mathrm{Pd}(\mathrm{dtbpf}) \mathrm{Cl}_{2}$ in combination with a Kolliphor EL/Span 80 7:3 mixture gives access, in quantitative yield, at room temperature in the air and without the use of any cosolvent, to DTBT. The reaction is so efficient that the product can be isolated at analytical purity directly by filtration of the reaction mixture over a sintered silica filter followed by washing with water and $\mathrm{MeOH}$.

The reaction was scaled up to $20 \mathrm{~g}$ of starting DBBF in order to precisely evaluate the E-factor. As the only organic waste produced was the $\mathrm{MeOH}$ employed for the final washing step (performed in a Soxhlet continuous extractor), we were able to get an E-factor as low as 4.7. The value raises to 10.7 when water and surfactants are included.

Water is not generally included in the calculation of E-factor, nonetheless heavy metal containing water has to be treated as an hazardous waste. Even thou in a previous communication, we demonstrated that the reaction medium, including the catalyst, can be recycled multiple times, in the case of DBBF we decided not to do so to privilege the ease of purification of the product obtained when using a fresh micellar solution. Indeed, recycling of the reaction medium leads to a crude product of lower purity, thus requiring chromatographic purification. The impact of such protocol on the Efactor is far greater than the benefit obtained recycling the reaction medium.

Our numbers can be compared with the values spanning from a minimum of 9.1 to a maximum of 48.8 , in all of the cases excluding purifications as no suitable data are available, for all other published routes (In the ESI we give an estimate of the E-factors including purification, based on standard column chromatography procedures. ${ }^{53}$ In such case the E-factors range from 274 to over 1900).

Tuning the reaction stoichiometry enables the control of mono vs diarylation, thus opening the way for the preparation of unsymmetrically substituted derivatives in a one pot procedure.

\section{One pot synthesis of asymmetrical derivatives.}


Entry 8 of Table 4 shows that when the reaction is carried out with a 1.5 to 1 stoichiometric ratio of 2 -thienylboronic acid over DBBF and in a Kolliphor EL/Tween 80 mixture, the product distribution is $83 \%$ monoarylated and $17 \%$ diarylated. In principle this result could open the way for the one pot synthesis of unsymmetrically substituted derivatives. According to the same Table however, the only way to drive the reaction to completion is to use a Kolliphor EL/Span 80 mixture. As such, we devised a two-step, but still one pot procedure, as no isolation of the intermediate monoarylation product is necessary. Firstly, we carried out the reaction according to the conditions reported in Table 4 , entry 8 . Once verified that no DBBF was left, we added a second aliquot of another arylboronic acid and as much Span 80 as it is required to reach the HLB value of 10.7 , necessary to drive the reaction to completion, thus giving access to unsymmetrically substituted derivatives. Scheme 6 shows the general reactions scheme as well as the examples we obtained of original 4,7-diaryl5,6-difluoro-2,1,3-benzothiadiazole derivatives.

Scheme 6. General reaction scheme for the synthesis of asymmetrical 4,7-diaryl-5,6-difluoro-2,1,3-benzothiadiazole derivatives. ${ }^{a}$ Low yield due to troublesome chromatographic separation. ${ }^{b}$ From the pinacol ester of the corresponding boronic acid.
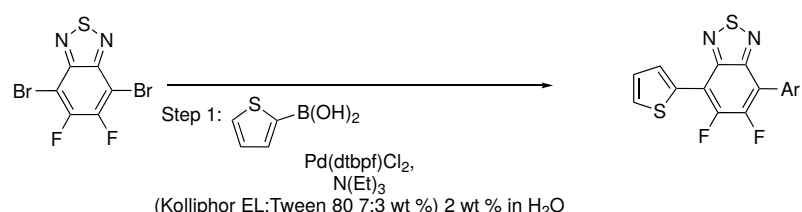

(Kolliphor EL:Tween $807: 3$ wt \%) 2 wt \% in $\mathrm{H}_{2} \mathrm{O}$
$3 \mathrm{~h}$, r.t

Step 2: $\mathrm{ArB}(\mathrm{OH})_{2}$, Span $80,12 \mathrm{~h}$ h r.t.

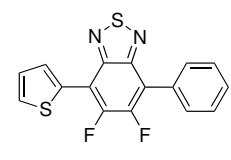

$5(52 \%)$

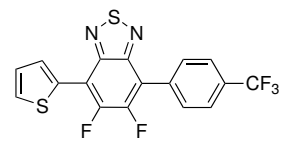

$8(33 \%)^{\mathrm{a}}$

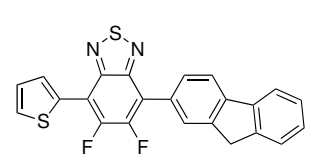

$11(80 \%)$

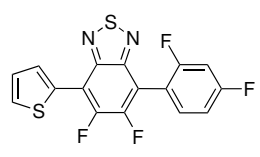

$6(50 \%)$

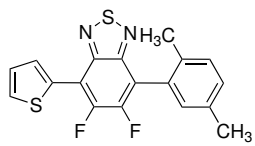

$9(53 \%)$
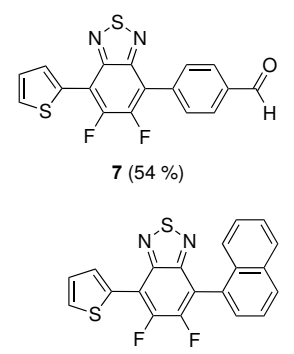

$10(54 \%)$

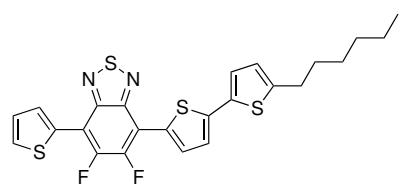

$12(40 \%)^{b}$

In details, DBBF:2-thienylboronic acid: $\mathrm{N}(\mathrm{Et})_{3}: \mathrm{Pd}(\mathrm{dtbpf}) \mathrm{Cl}_{2}$ are mixed in the 1:1.5:6:0.02 proportion working at $0.5 \mathrm{M}$ concentration of DBBF. The reaction is stirred at room temperature for $3 \mathrm{~h}$. At this stage the GC-MS analysis of the reaction mixture only shows traces of unreacted DBBF. 1.5 equivalents of a different boronic acid (or pinacol ester) are added along with Span 80, and mixture is stirred at r.t. overnight. The final unsymmetrically substituted derivatives are isolated by chromatographical purification of the reaction mixture.

All reactions proceed till complete conversion of the TBF remained after the first step. We did not observe the formation of byproducts, other than the DTBT formed in the first step. 
The moderate to good isolated yields shown in Scheme 6 are limited by the sometimes troublesome (particularly in the case of derivatives 8 and 12) chromatographic purification of the target product from DTBT.

All unsymmetrically substituted derivatives we made are original and could have direct applications as luminescent compounds in applications the like of Luminescent Solar Collectors, bio-imaging or OLEDs. Indeed, they all share a good separation between absorption and emission spectra (Stokes Shifts) connected with a moderate to good emission efficiency. Figure 1 and Table 5 summarize the most relevant features of the absorption and emission spectra for all new compounds. The magnitude of the Stokes Shift, alongside with moderate to good values of emission quantum yields make derivatives 5, 7, 10 and $\mathbf{1 1}$ particularly interesting for applications like bioimaging, where the use of the benzothiadiazole core is already well documented ${ }^{54-56}$. For further details, see the ESI file.

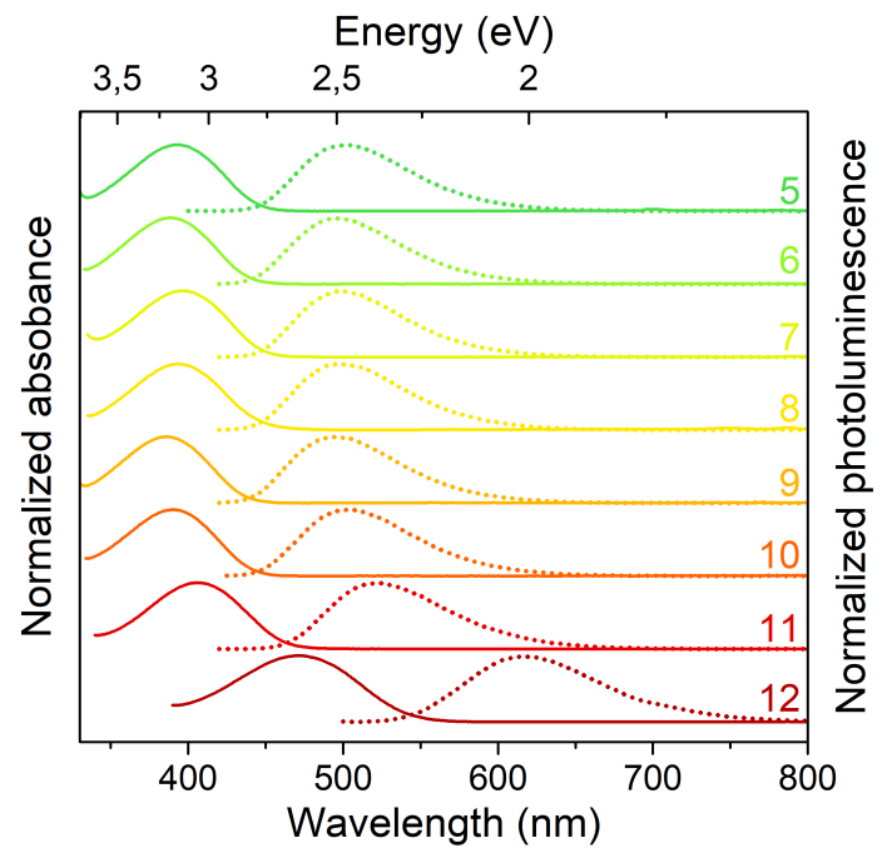

Figure 1. Normalized absorption (solid line) and emission (dotted line) spectra for derivatives 5-12 in $\mathrm{CH}_{2} \mathrm{Cl}_{2}$ solution.

Table 5. Optical properties (absorption and emission maxima, Stokes Shift, molar extinction coefficient and emission quantum yield) for derivatives 7-12 in $\mathrm{CH}_{2} \mathrm{Cl}_{2}$ solution. 


\begin{tabular}{cccccc}
\hline Derivative & Eabs $(\mathrm{eV}) / \lambda_{\text {abs }}(\mathrm{nm})$ & Eem $(\mathrm{eV})$ & Stokes Shift $(\mathrm{eV})$ & $\varepsilon\left(\mathrm{M}^{-1} \mathrm{~cm}^{-1}\right)$ & $\Phi^{\mathrm{a}}(\%)$ \\
\hline 5 & $3.16 / 392$ & 2.47 & 0.69 & 13400 & 83 \\
6 & $3.19 / 389$ & 2.50 & 0.69 & 10100 & 70 \\
7 & $3.12 / 396$ & 2.49 & 0.63 & 18000 & 99 \\
8 & $3.15 / 393$ & 2.49 & 0.66 & 11400 & 74 \\
9 & $3.21 / 386$ & 2.52 & 0.69 & 9700 & 66 \\
10 & $3.18 / 390$ & 2.46 & 0.72 & 9100 & 39 \\
11 & $3.05 / 406$ & 2.37 & 0.68 & 17550 & 90 \\
12 & $2.63 / 472$ & 2.01 & 0.62 & 24300 & 44
\end{tabular}

a Relative to DTBT (Ф 0.96) as the standard.

\section{Generality of the approach and recyclability of the reaction medium.}

In order to further support the suitability of the Kolliphor EL/Span 80 reaction mixture as a superior micellar medium to carry out reactions leading to an over decrease in the polarity on going from starting materials to the products, we revisited two reactions we had trouble with in the past using Kolliphor EL alone as the surfactant. The first derivative, the bithiophene 13, is the starting material for the preparation of another relevant building block for organic photovoltaics we recently introduced: dithienocyclohexanone $(\mathrm{DTCH})^{5}$. In our previous paper we could not prepare 13 by means of a micellar SM coupling and we reverted to a direct arylation approach in standard organic solvent based conditions. When we carried out the SM coupling of methyl 2-(2-bromothiophen-3-yl)acetate and 2-thyenylboronic acid using a 2 wt\% Kolliphor EL/Span 80 7:3 mixture under the same conditions optimized for the preparation of DTBT, the reaction gave complete conversion and an isolated yield of $98 \%$ (Scheme 7 ). Actually, the coupling was so efficient that the reaction mixture reached $45^{\circ} \mathrm{C}$ spontaneously, soon after the addition of the amine.

Scheme 7. SM micellar coupling between methyl 2-(2-bromothiophen-3-yl)acetate and 2-thienylboronic acid in a $2 \%$ by weight solution of Kolliphor EL/Span 80 7:3 mixture.
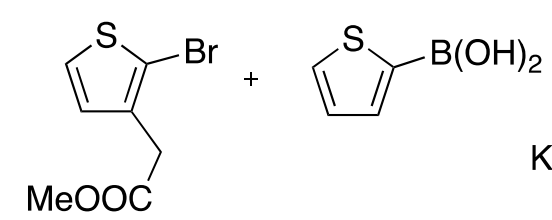

$\mathrm{Pd}(\mathrm{dtbpf}) \mathrm{Cl}_{2} / \mathrm{NEt}_{3}$ Kolliphor EL/Span 80 7:3 wt 2\% $2 h$, r.t.

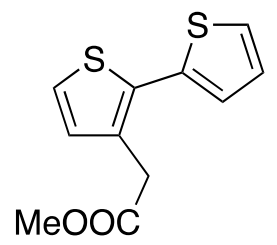

$98 \%$

13

Even more impressively, we obtained essentially quantitative yield also when working with 9-bromoanthracene: in the past we obtained good results with this substrate with Kolliphor EL only when working at high formal concentration of 
bromide and boronic acid and with a large excess of the latter. ${ }^{40}$ The use of the Kolliphor EL/Span 80 7:3 mixture not only enables the preparation of 9-phenylanthracene in quantitative yield in less than 30 minutes, but it also gives an impressive demonstration of the robustness of such mixture to oxygen deactivation. Indeed, thanks to the highly crystalline nature of 9-phenylanthracene we could proceed to the work-up of the reaction by simple suction filtration followed by crystallization of the crude precipitate thus obtained. We thus proceeded to the recycling of the reaction medium, without addition of any further aliquot of catalyst. In the second run the reaction performed identically, if not for a little increase of the reaction time that raised to $2 \mathrm{~h}$. The product was again isolated by suction filtration and the reaction medium recycled. We still observed quantitative conversion and isolated yields exceeding $95 \%$ up to the fourth run. We consistently had to increase the reaction time, no doubt as the multiple filtration of the reaction product gradually lowered the concentration of the catalyst. Scheme 8 summarizes the results as well as the evolution of the reaction Efactor as a function of the recycling runs. Even though such kind of very low E-factors upon recycling are documented in the literature, no such result has ever been obtained without the addition of fresh catalyst after every run.

Scheme 8. Study of the recycling of the reaction medium in the SM micellar coupling of phenylboronic acid and 9-bromoanthracene in a $2 \%$ by weight water solution of Kolliphor EL/Span 80 7:3 mixture.

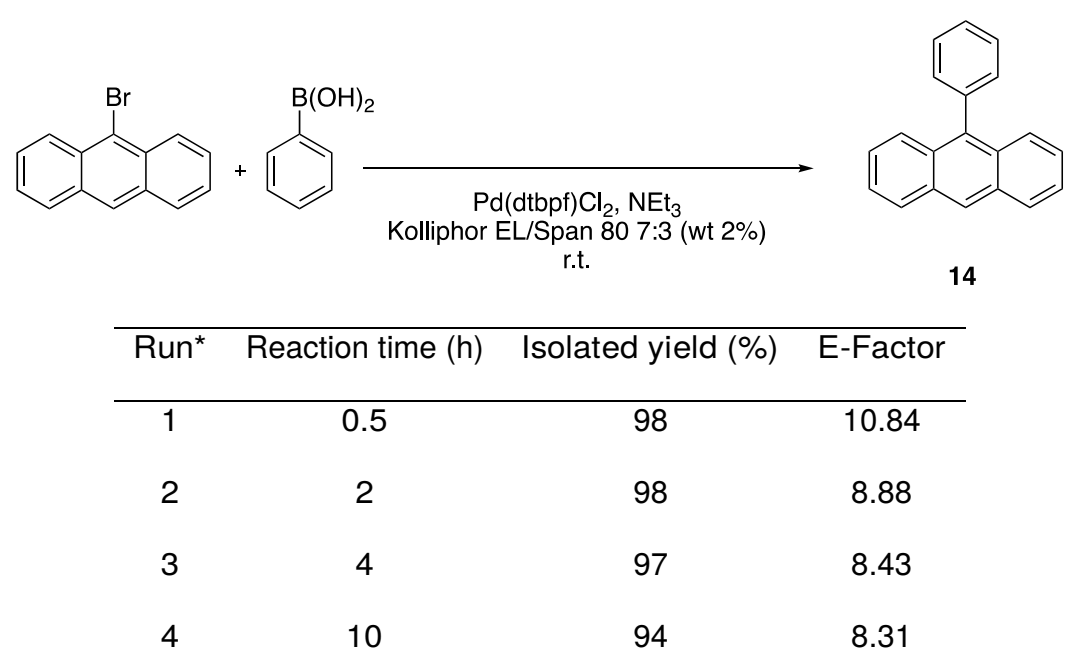

* After each run, reaction mixture was filtered and product crystallized. 9-bromoanthracene, phenylboronic acid and NEt3 only were added to the filtrate for the subsequent run.

\section{CONCLUSIONS}

Micellar reactions are rapidly revolutionising established synthetic methods. In particular, the micellar Suzuki-Miyaura coupling represents one of the most successful examples of the capability of such techniques to dramatically improve sustainability while maintaining performances. When not immediately satisfactory, particular reactions might require tuning of conditions while moving from standard organic solvent to micellar environment. The peculiar characteristic of micro-heterogeneous micellar reactions requires a specifically devised approach where tuning of common reaction 
parameters (concentration, temperature time, catalyst) has to go hand in hand with the toolbox of the formulation chemist. In the case of the synthesis of the popular conjugated building block DTBT and of several unsymmetrically substituted derivatives of the same family, reactions can be driven to completion only when the characteristics of the employed micellar environment are appropriate. The dedicated literature so far approached the problem of underperforming reactions by the introduction of new, improved surfactants. We show that the careful selection and mixing of readily available and fully sustainable commercial surfactants can lead to complete conversion where single component micellar solutions fail. We particularly focused on Kolliphor EL as the main micellar forming surfactants and on Tween 80 and Span 80 as hydrophilic and lipophilic co-surfactants respectively.

We offer an interpretation of the data based on the preferential interaction of reagents vs products with micelles assembled with one or more surfactants, hampering or speeding up the reaction depending on the micelles dominating lipophilic over hydrophilic character. In particular we have found an empirical correlation between the surfactant mixture HLB value and the performance of the reaction in all cases when the polarity of reagents and products is remarkably different.

Within such optimized micellar environment, it is possible to control the degree of mono vs diarylation to the point of being able to prepare unsymmetrically substituted derivatives by the sequential reaction of DBBF with two different arylboronic acids.

The fact that all reactions were performed under standard laboratory conditions with no need for inert gases and any pre-treatment of water and surfactants offers an additional relevant solicitation for the widespread application of micellar methods in everyday laboratory practices.

\section{EXPERIMENTAL SECTION}

\section{General Information.}

Reagents and solvents were bought from TCI, Fluorochem and Sigma-Aldrich and used as received. GC-MS spectra were collected on a Clarus 560 S PerkinElmer having an Elite-5MS 30.0 m x $250 \mu \mathrm{m}$ column. Helium was used as carrier gas. NMR spectra were collected on a Bruker NMR Avance 400 NEO. Absorption spectra of derivatives 5-12 were collected on a Cary $60 \mathrm{UV}$-Vis Agilent Spectrophotometer in a $10 \mathrm{~mm}$ pathlength quartz cuvette. Photoluminescence spectra of derivatives 5-12 were collected on a Cary Eclipse Fluorescence Agilent Spectrophotometer in a 10 mm pathlength quartz cuvette. DLS experiments were performed on a 90Plus Particle Size Analyzer (Brookhaven Instruments Corporation) with scattering angles of $15^{\circ}$ and $90^{\circ}$, equipped with a $35 \mathrm{~mW}$ solid state $632,8 \mathrm{~nm}$ laser and a Brookhaven's TuboCorr correlator with 510 channels.

\section{General synthetic procedure for derivative DTBT.}

Reactions were carried in a round bottom vial. Depending on the experiment, the boronic acid (Scheme 3), the concentration (Table 1), amount (Table 2) and nature (Table 3-4) of surfactant dispersion, and the catalyst (Table 4) 
vary. DBBF (165 mg, $0.5 \mathrm{mmol})$ and the boronic acid $(1.5 \mathrm{mmol})$ are weighted in the vial, then $1 \mathrm{~mL}$ of surfactant dispersion in water is added. The mixture is stirred, then $\mathrm{N}(\mathrm{Et})_{3}(303 \mathrm{mg}, 3.0 \mathrm{mmol})$ is added. The mixture is allowed to homogenize for 5 minutes before addition of the catalyst $(0.01 \mathrm{mmol})$. All reactions were quenched after $12 \mathrm{~h}$ stirring at room temperature, extracted with $\mathrm{CH}_{2} \mathrm{Cl}_{2}$, filtered over a pad of silica gel and submitted to GC-MS characterization.

Scaled synthesis of 4,7-di(thiophen-2-yl)-5,6-difluoro-2,1,3-benzothiadiazole (DTBT) and calculation of E-factor.

$\operatorname{DBBF}(20.0 \mathrm{~g}, 60.6 \mathrm{mmol})$ and 2-thienylboronic acid $(23.3 \mathrm{~g}, 182 \mathrm{mmol})$ are weighted in a $500 \mathrm{~mL}$ roundbottom flask, then $121 \mathrm{~mL}$ of $2 \%$ (Kolliphor EL/Span 80 7:3) dispersion in water are added. The mixture is stirred with a mechanical stirrer, then $\mathrm{N}(\mathrm{Et})_{3}(36.7 \mathrm{~g}, 364 \mathrm{mmol})$ is added. The mixture is allowed to homogenize before addition of $\mathrm{Pd}(\mathrm{dtbpf}) \mathrm{Cl}_{2}$ $(1.580 \mathrm{~g}, 2.42 \mathrm{mmol})$. After $12 \mathrm{~h}$, the reaction mixture is filtered over a sintered silica filter and washed with deionized water. The crude solid was finally purified by hot washing with $\mathrm{MeOH}(40 \mathrm{~mL})$ in a Soxhlet continuous extractor to remove residual TBF. The product was recovered as a bright yellow solid. (19.8 g, 97\% yield). Characterizations are in agreement with previously published data. ${ }^{57}$

E-factor $=\frac{\text { mass of by-products }+ \text { mass of solvents }}{\text { mass of product }}$

$$
=\frac{36.7\left(\mathrm{~N}(\mathrm{Et})_{3}\right)+2.7(\operatorname{surf} .)+31.68(\mathrm{MeOH})+22.79(\text { excess boronic and boron containg byproducts })}{19.8}=4.7
$$

Including water

E-factor $=\frac{\text { mass of by-products }+ \text { mass of solvents }}{\text { mass of product }}=\frac{\left.36.7\left(\mathrm{~N}(\mathrm{Et})_{3}\right)+31.68(\mathrm{MeOH})+22.79 \text { (boron }\right)+121(\text { mic. solution })}{19.8}=10.7$

${ }^{1} \mathrm{H}$ NMR $\left(\mathrm{CDCl}_{3}, 400 \mathrm{MHz}\right): \delta 8.30(\mathrm{dd}, \mathrm{J}=3.9,1.1 \mathrm{~Hz}, 2 \mathrm{H}), 7.62(\mathrm{dd}, \mathrm{J}=5.2,1.1 \mathrm{~Hz}, 2 \mathrm{H}), 7.27(\mathrm{~m}, 2 \mathrm{H}) ;{ }^{13} \mathrm{C}\left\{{ }^{1} \mathrm{H}\right\} \mathrm{NMR}$ $\left(\mathrm{CDCl}_{3}, 100 \mathrm{MHz}\right): \delta 149.7(\mathrm{dd}, \mathrm{J}=260.0,20.4 \mathrm{~Hz}), 148.9(\mathrm{t}, \mathrm{J}=4.4 \mathrm{~Hz}), 131.5,130.9(\mathrm{t}, \mathrm{J}=3.9 \mathrm{~Hz}), 128.9(\mathrm{t}, \mathrm{J}=3.1 \mathrm{~Hz})$, $127.4,111.8(\mathrm{~d}, \mathrm{~J}=9.4 \mathrm{~Hz})$.

Synthesis of 4,7-di(thiophen-3-yl)-5,6-difluoro-2,1,3-benzothiadiazole (3).

DBBF (165 mg, $0.5 \mathrm{mmol}$ ) and 3-thienylboronic acid (192 mg, $1.5 \mathrm{mmol}$ ) are weighted in a Biotage microwave vial, then $1 \mathrm{~mL}$ of $2 \%$ (Kolliphor EL/Span $807: 3$ ) dispersion in water is added. The mixture is stirred, then $\mathrm{N}(\mathrm{Et}){ }_{3}(303 \mathrm{mg}, 3.0$ $\mathrm{mmol})$ is added. The mixture is allowed to homogenize for 5 minutes before addition of $\mathrm{Pd}(\mathrm{dtbpf}) \mathrm{Cl}_{2}(13.1 \mathrm{mg}, 0.02$ $\mathrm{mmol}$ ). After $5 \mathrm{~h}$, the reaction is diluted with $10 \mathrm{~mL}$ of water and filtered. The crude is crystallized from heptane to afford $153 \mathrm{mg}$ of the pure product as yellow needles (91\% yield). $\mathrm{mp} 110.9-111.8{ }^{\circ} \mathrm{C} ;{ }^{1} \mathrm{H} \mathrm{NMR}\left(\mathrm{CDCl}_{3}, 400 \mathrm{MHz}\right): \delta 8.37(\mathrm{dd}$, $\mathrm{J}=3.0,1.3 \mathrm{~Hz}, 2 \mathrm{H}), 7.94(\mathrm{dq}, \mathrm{J}=5.1,1.1 \mathrm{~Hz}, 2 \mathrm{H}), 7.51(\mathrm{dd}, \mathrm{J}=5.1,3.0 \mathrm{~Hz}, 2 \mathrm{H}) ;{ }^{13} \mathrm{C}\left\{{ }^{1} \mathrm{H}\right\} \mathrm{NMR}\left(\mathrm{CDCl}_{3}, 100 \mathrm{MHz}\right): \delta 150.5$ (dd, J=258.6, 20.4 Hz), 150.0, 130.2, 128.9 (t, J=2.9 Hz), 128.2, 125.2, 113.1; anal. calcd for $\mathrm{C}_{14} \mathrm{H}_{6} \mathrm{~F}_{2} \mathrm{~N}_{2} \mathrm{~S}_{3}: \mathrm{C}_{4} 49.98 ; \mathrm{H}_{\text {, }}$ $1.80 ; \mathrm{N}, 8.33$; found: C, 49.53; H, 1.52; N, 8.02.

\section{Synthesis of 4,7-diphenyl-5,6-difluoro-2,1,3-benzothiadiazole (4).}

DBBF (165 mg, $0.5 \mathrm{mmol})$ and phenylboronic acid (183 mg, $1.5 \mathrm{mmol})$ are weighted in a Biotage microwave vial, then $1 \mathrm{~mL}$ of $2 \%$ (Kolliphor $10 \%$ ) dispersion in water is added. The mixture is stirred, then $\mathrm{N}(\mathrm{Et})$ ( $_{3}(303 \mathrm{mg}, 3.0 \mathrm{mmol})$ is added. The mixture is allowed to homogenize for 5 minutes before addition of $\mathrm{Pd}(\mathrm{dtbpf}) \mathrm{Cl}_{2}(13.1 \mathrm{mg}, 0.02 \mathrm{mmol})$. After $12 \mathrm{~h}$, 
the reaction is diluted with $10 \mathrm{~mL}$ of water and filtered. The crude is crystallized from heptane to afford $153 \mathrm{mg}$ of the pure product as white needles (95\% yield). mp 205.0-205.8 ${ }^{\circ} \mathrm{C} ;{ }^{1} \mathrm{H} \mathrm{NMR}\left(\mathrm{CDCl}_{3}, 400 \mathrm{MHz}\right): \delta 7.83(\mathrm{~d}, \mathrm{~J}=7.4 \mathrm{~Hz}, 4 \mathrm{H})$, $7.59(\mathrm{t}, \mathrm{J}=7.5 \mathrm{~Hz}, 4 \mathrm{H}), 7.52(\mathrm{t}, \mathrm{J}=7.4 \mathrm{~Hz}, 2 \mathrm{H}) ;{ }^{13} \mathrm{C}\left\{{ }^{1} \mathrm{H}\right\} \mathrm{NMR}\left(\mathrm{CDCl}_{3}, 100 \mathrm{MHz}\right): \delta 151.4(\mathrm{t}, \mathrm{J}=3.9 \mathrm{~Hz}), 151.3$ (dd, J=258.6, 20.4 Hz), 131.4, 131.1, 130.0, 129.4, 119.7 (dd, J=10.5, 4.4 Hz); anal. calcd for $\mathrm{C}_{18} \mathrm{H}_{10} \mathrm{~F}_{2} \mathrm{~N}_{2} \mathrm{~S}: \mathrm{C}, 66.65 ; \mathrm{H}, 3.11 ; \mathrm{N}, 8.64$; found: C, 66.26; H, 2.76; N, 8.54.

\section{Synthesis of 4-bromo-7-(thiophen-2-yl)-5,6-difluoro-2,1,3-benzothiadiazole (TBF).}

DBBF (330 mg, $1.0 \mathrm{mmol})$ and 3-thienylboronic acid (192 mg, $1.5 \mathrm{mmol})$ are weighted in a Biotage microwave vial, then $2 \mathrm{~mL}$ of $10 \%$ Kolliphor EL dispersion in water is added. The mixture is stirred, then $\mathrm{N}(\mathrm{Et}){ }_{3}(303 \mathrm{mg}, 3.0 \mathrm{mmol})$ is added. The mixture is allowed to homogenize for 5 minutes before addition of $\mathrm{Pd}(\mathrm{dtbpf}) \mathrm{Cl}_{2}(13.2 \mathrm{mg}, 0.02 \mathrm{mmol})$. After $12 \mathrm{~h}$, the reaction is diluted with $10 \mathrm{~mL}$ of water and filtered. The crude is purified by column chromatography using heptane:toluene $=7: 3$ as eluent. Isolated product: $187 \mathrm{mg}\left(56 \%\right.$ yield), yellow powder. $\mathrm{mp} 156.5-157.3 ;{ }^{1} \mathrm{H} \mathrm{NMR}(\mathrm{CDCl} 3$, $400 \mathrm{MHz}): \delta 8.26(\mathrm{ddd}, \mathrm{J}=3.9,1.1,0.7 \mathrm{~Hz}, 1 \mathrm{H}), 7.64(\mathrm{dd}, \mathrm{J}=5.2,1.1 \mathrm{~Hz}, 1 \mathrm{H}), 7.27(\mathrm{ddd}, \mathrm{J}=5.2,3.9,1.4 \mathrm{~Hz}, 1 \mathrm{H}) ;{ }^{13} \mathrm{C}\left\{{ }^{1} \mathrm{H}\right\}$ $\operatorname{NMR}\left(\mathrm{CDCl}_{3}, 100 \mathrm{MHz}\right): \delta 152.4$ (dd, J=256.5, 20.3 Hz), 149.1 (dd, J=262.3, 19.0 Hz), 149.9 (d, J=5.1 Hz), 147.9, 131.4 (d, J=8.7 Hz), 130.8 (dd, J=5.8, 3.6 Hz), 129.5 (d, J=6.6 Hz), 127.5, 113.4 (dd, J=12.3 Hz, 1.4 Hz), 97.1 (dd, J=21.8, 1.4 $\mathrm{Hz}$ ); anal. calcd for $\mathrm{C}_{10} \mathrm{H}_{3} \mathrm{BrF}_{2} \mathrm{~N}_{2} \mathrm{~S}_{2}: \mathrm{C}, 36.05 ; \mathrm{H}, 0.91 ; \mathrm{N}, 8.41$; found: $\mathrm{C}, 36.03 ; \mathrm{H}, 0.61 ; \mathrm{N}, 8.32$.

\section{General synthetic procedure for asymmetrical derivatives.}

Reactions were carried in a Biotage microwave vial. DBBF (330 mg, $1.0 \mathrm{mmol})$, 2-thienylboronic acid (192 mg, $1.5 \mathrm{mmol})$ and $\mathrm{Pd}(\mathrm{dtbpf}) \mathrm{Cl}_{2}(26.3 \mathrm{mg}, 0.04 \mathrm{mmol})$ are weighted in the vessel, then $2 \mathrm{~mL}$ of $2 \%$ (Kolliphor/Tween 7:3) dispersion in water are added. The mixture is allowed to homogenize for 5 minutes before addition of $\mathrm{N}(\mathrm{Et}))_{3}(607 \mathrm{mg}, 6.0 \mathrm{mmol})$. The reaction is stirred for $3 \mathrm{~h}$, then $1.5 \mathrm{mmol}$ of the $2^{\text {nd }}$ boronic acid/ester are added in the vessel. $20 \mathrm{mg}$ of Span 80 are added as well. The reaction is stirred overnight, and subsequently diluted with $10 \mathrm{~mL}$ of water and filtered. The crude was finally purified by column chromatography or crystallization.

4-phenyl-7-(thiophen-2-yl)-5,6-difluoro-2, 1,3-benzothiadiazole (5). The crude is purified by column chromatography using heptane:DCM=8:2 as eluent. Isolated product: $172 \mathrm{mg}(52 \%)$, lime green powder. $\mathrm{mp} 164.7-165.2^{\circ} \mathrm{C}$; ${ }^{1} \mathrm{H} \mathrm{NMR}$ $\left(\mathrm{CDCl}_{3}, 400 \mathrm{MHz}\right): \delta 8.31(\mathrm{~d}, \mathrm{~J}=3.9 \mathrm{~Hz}, 1 \mathrm{H}), 7.82(\mathrm{~d}, \mathrm{~J}=8.3 \mathrm{~Hz}, 2 \mathrm{H}), 7.63(\mathrm{dd}, \mathrm{J}=5.3,0.9 \mathrm{~Hz}, 1 \mathrm{H}), 7.58(\mathrm{t}, \mathrm{J}=7.4,0.9$ $\mathrm{Hz}, 2 \mathrm{H}), 7.49-7.52(\mathrm{~m}, 1 \mathrm{H}), 7.29(\mathrm{~m}, 1 \mathrm{H}) ;{ }^{13} \mathrm{C}\left\{{ }^{1} \mathrm{H}\right\} \mathrm{NMR}\left(\mathrm{CDCl}_{3}, 100 \mathrm{MHz}\right): \delta 151.33(\mathrm{~d}, 8.6 \mathrm{~Hz}), 151.32(\mathrm{dd}, \mathrm{J}=255.9$, $19.0 \mathrm{~Hz}), 150.6(\mathrm{dd}, \mathrm{J}=259.8,20.0 \mathrm{~Hz}), 149.9(\mathrm{~d}, \mathrm{~J}=8.8 \mathrm{~Hz}), 132.4(\mathrm{dd}, \mathrm{J}=5.4,3.4 \mathrm{~Hz}), 131.9(\mathrm{~d}, \mathrm{~J}=8.3 \mathrm{~Hz}), 131.4$ $(\mathrm{d}, \mathrm{J}=2.6 \mathrm{~Hz}), 131.1,130.0,129.8(\mathrm{~d}, \mathrm{~J}=6.4 \mathrm{~Hz}), 129.4,128.3,118.7(\mathrm{~d}, \mathrm{~J}=14.2 \mathrm{~Hz}), 113.6(\mathrm{dd}, \mathrm{J}=12.2,1.2 \mathrm{~Hz})$; anal. calcd for $\mathrm{C}_{16} \mathrm{H}_{8} \mathrm{~F}_{2} \mathrm{~N}_{2} \mathrm{~S}_{2}$ : C, 58.17; $\mathrm{H}, 2.44 ; \mathrm{N}, 8.48$; found: $\mathrm{C}, 57.82 ; \mathrm{H}, 2.12 ; \mathrm{N}, 8.45$.

4-(2,4-difluorophenyl)-7-(thiophen-2-yl)-5,6-difluoro-2,1,3-benzothiadiazole (6). The crude is purified by column chromatography using heptane:toluene=7:3 as eluent. Isolated product: $183 \mathrm{mg}(50 \%)$, orange powder. $\mathrm{mp} 166.6-167.8$ ${ }^{\circ} \mathrm{C} ;{ }^{1} \mathrm{H}$ NMR $\left(\mathrm{CDCl}_{3}, 400 \mathrm{MHz}\right): \delta 8.35$ (ddd, J=3.8, 1.2, 0.6 Hz, 1H), 7.62-7.68 (m, 2H), 7.31 (ddd, J=5.2, 3.8, $1.4 \mathrm{~Hz}$, $1 \mathrm{H}), 7.05-7.15(\mathrm{~m}, 2 \mathrm{H}) ;{ }^{13} \mathrm{C}\left\{{ }^{1} \mathrm{H}\right\} \mathrm{NMR}\left(\mathrm{CDCl}_{3}, 100 \mathrm{MHz}\right): \delta 163.8(\mathrm{dd}, \mathrm{J}=252.1,11.6 \mathrm{~Hz}), 160.5(\mathrm{dd}, \mathrm{J}=253.4,12.3 \mathrm{~Hz})$, 
151.2 (dd, J=260.7, 21.1 Hz), 150.3 (d, J=8.8 Hz), 149.4 (dd, J=265.1, 23.2 Hz), 148.8 (d, J=8.7 Hz), 133.2 (dd, J=9.9, 3.7 Hz), 131.4 (d, J=8.3 Hz), 131.2, 129.3 (d, J=6.5 Hz), 127.5, 114.1 (d, J=16.1), 113.8 (d, J=11.7 Hz), 111.8 (dd, $\mathrm{J}=21.7,3.6 \mathrm{~Hz}), 111.2(\mathrm{~d}, \mathrm{~J}=16.0 \mathrm{~Hz}), 104.7$ (t, J=25.5 Hz); anal. calcd for $\mathrm{C}_{16} \mathrm{H}_{6} \mathrm{~F}_{4} \mathrm{~N}_{2} \mathrm{~S}_{2}: \mathrm{C}, 52.45 ; \mathrm{H}, 1.65 ; \mathrm{N}, 7.65$; found: C, 52.07; H, 1.31; N, 7.59.

4-(4-formylphenyl)-7-(thiophen-2-yl)-5,6-difluoro-2,1,3-benzothiadiazole (7). The crude is purified by column chromatography using heptane:DCM=8:2 as eluent. Isolated product: $194 \mathrm{mg}(54 \%)$, orange powder. $\mathrm{mp} 171.1-171.4$ ${ }^{\circ} \mathrm{C} ;{ }^{1} \mathrm{H} \mathrm{NMR}\left(\mathrm{CDCl}_{3}, 400 \mathrm{MHz}\right): \delta 10.17(\mathrm{~s}, 1 \mathrm{H}), 8.38(\mathrm{ddd}, \mathrm{J}=3.8,1.1,0.7 \mathrm{~Hz}, 1 \mathrm{H}), 8.09-8.12(\mathrm{~m}, 2 \mathrm{H}), 8.03-8.06(\mathrm{~m}, 2 \mathrm{H})$, $7.69(\mathrm{dd}, \mathrm{J}=5.1,1.1 \mathrm{~Hz}, 1 \mathrm{H}), 7.33(\mathrm{ddd}, \mathrm{J}=5.3,3.9,1.4 \mathrm{~Hz}, 1 \mathrm{H}) ;{ }^{13} \mathrm{C}\left\{{ }^{1} \mathrm{H}\right\} \mathrm{NMR}\left(\mathrm{CDCl}_{3}, 100 \mathrm{MHz}\right): \delta 191.7,150.9(\mathrm{dd}$, J=259.3, $19.6 \mathrm{~Hz}), 149.9(\mathrm{~d}, \mathrm{~J}=8.0 \mathrm{~Hz}), 149.4$ (dd, J=260.6, $19.6 \mathrm{~Hz}), 149.0$ (d, J=8.7 Hz), $136.3,136.2$ (m), 131.5 (d, J=8.7 Hz), 131.3 (d, J=2.9 Hz), 131.2, 129.7, 129.5 (d, J=6.5 Hz), 127.5, 116.2 (d, J=13.8 Hz), 113.8 (dd, J=12.5, 2.1 $\mathrm{Hz}$ ); anal. calcd for $\mathrm{C}_{17} \mathrm{H}_{8} \mathrm{~F}_{2} \mathrm{~N}_{2} \mathrm{OS}_{2}$ : C, 56.97; H, 2.25; N, 7.82; found: C, 56.64; H, 1.94; N, 7.77.

4-(4-(trifluoromethyl)phenyl)-7-(thiophen-2-yl)-5,6-difluoro-2, 1,3-benzothiadiazole (8). No eluent combination allowed to separate chromatographically the product from DTBT. Therefore, the crude was refluxed in methanol and hot filtered twice to remove the symmetrical DTBT derivative. The obtained solid was then crystallized three times from heptane. Isolated product: $131 \mathrm{mg}(33 \%)$, yellow needles. $\mathrm{mp} 124.7-125.3{ }^{\circ} \mathrm{C} ;{ }^{1} \mathrm{H} \mathrm{NMR}\left(\mathrm{CDCl}_{3}, 400 \mathrm{MHz}\right): \delta 8.37$ (ddd, J=3.8, 1.0, $0.7 \mathrm{~Hz}, 1 \mathrm{H}), 7.97-8.00(\mathrm{~m}, 2 \mathrm{H}), 7.84-7.87(\mathrm{~m}, 2 \mathrm{H}), 7.69(\mathrm{dd}, \mathrm{J}=5.1,1.1 \mathrm{~Hz}, 1 \mathrm{H}), 7.33$ (ddd, J=5.2, 3.9, $1.4 \mathrm{~Hz}, 1 \mathrm{H})$; ${ }^{13} \mathrm{C}\left\{{ }^{1} \mathrm{H}\right\} \mathrm{NMR}\left(\mathrm{CDCl}_{3}, 100 \mathrm{MHz}\right): \delta 150.8(\mathrm{dd}, \mathrm{J}=257.9,18.9 \mathrm{~Hz}), 150.0(\mathrm{~d}, \mathrm{~J}=8.7 \mathrm{~Hz}), 149.3$ (dd, J=260.7, $\left.19.6 \mathrm{~Hz}\right)$, $149.0(\mathrm{~d}, \mathrm{~J}=8.7 \mathrm{~Hz}), 133.8(\mathrm{~m}), 131.4(\mathrm{~d}, \mathrm{~J}=8.7 \mathrm{~Hz}), 131.3(\mathrm{~m}), 131.01(\mathrm{q}, \mathrm{J}=32.7 \mathrm{~Hz}), 130.95(\mathrm{~d}, \mathrm{~J}=2.9 \mathrm{~Hz}), 129.4(\mathrm{~d}$, $\mathrm{J}=6.5 \mathrm{~Hz}), 127.5,125.5(\mathrm{q}, \mathrm{J}=3.6 \mathrm{~Hz}), 124.0$ (q, J=272.5 Hz), 116.1 (d, J=13.8 Hz), 113.7 (dd, J=12.3, 2.1 Hz); anal. calcd for $\mathrm{C}_{17} \mathrm{H}_{7} \mathrm{~F}_{5} \mathrm{~N}_{2} \mathrm{~S}_{2}$ : C, 51.25; $\mathrm{H}, 1.77 ; \mathrm{N}, 7.03$; found: $\mathrm{C}, 50.90 ; \mathrm{H}, 1.42 ; \mathrm{N}, 6.99$.

4-(2,5-dimethylphenyl)-7-(thiophen-2-yl)-5,6-difluoro-2,1,3-benzothiadiazole (9). The crude is purified by column chromatography using petroleum ether:toluene=8:2 as eluent. Isolated product: $190 \mathrm{mg}(53 \%)$, yellow powder. mp 96.8$97.3^{\circ} \mathrm{C} ;{ }^{1} \mathrm{H} \mathrm{NMR}\left(\mathrm{CDCl}_{3}, 400 \mathrm{MHz}\right): \delta 8.33(\mathrm{ddd}, \mathrm{J}=3.8,1.1,0.6 \mathrm{~Hz}, 1 \mathrm{H}), 7.64(\mathrm{dd}, \mathrm{J}=5.1,1.1 \mathrm{~Hz}, 1 \mathrm{H}), 7.28-7.32(\mathrm{~m}$, 2H), 7.24-7.26 (m, 1H), $7.20(\mathrm{br}, 1 \mathrm{H}), 2.41(\mathrm{~s}, 3 \mathrm{H}), 2.15(\mathrm{~s}, 3 \mathrm{H}) ;{ }^{13} \mathrm{C}\left\{{ }^{1} \mathrm{H}\right\} \mathrm{NMR}\left(\mathrm{CDCl}_{3}, 100 \mathrm{MHz}\right): \delta 150.9(\mathrm{~d}, \mathrm{~J}=8.7 \mathrm{~Hz})$, 150.4 (dd, J=255.0, 18.9 Hz), 149.7 (dd, J=260.9, $19.7 \mathrm{~Hz}$ ), 148.8 (d, J=8.7 Hz), 135.4, 134.2, 131.5 (dd, J=5.8, 3.6 Hz Hz), 131.02, 131.00 (d, J=8.7 Hz), 130.5, 130.3, 129.4 (d, J=1.1 Hz), 128.9 (d, J=6.5 Hz), 127.4, 118.2 (d, J=16.4 Hz), 112.9 (dd, J=12.4, $1.4 \mathrm{~Hz}$ ), 21.0, 19.6 (d, J=1.5 Hz); anal. calcd for $\mathrm{C}_{18} \mathrm{H}_{12} \mathrm{~F}_{2} \mathrm{~N}_{2} \mathrm{~S}_{2}: \mathrm{C}, 60.32 ; \mathrm{H}, 3.37 ; \mathrm{N}, 7.82 ;$ found: C, $60.46 ; \mathrm{H}, 3.41 ; \mathrm{N}, 7.56$.

4-(naphthalen-1-yl)-7-(thiophen-2-yl)-5,6-difluoro-2,1,3-benzothiadiazole (10). The crude is purified by column chromatography using heptane:DCM=8:2 as eluent. Isolated product: $207 \mathrm{mg}$ (54\%), yellow powder. mp 149.0-149.5 ${ }^{\circ} \mathrm{C} ;{ }^{1} \mathrm{H} \mathrm{NMR}\left(\mathrm{CDCl}_{3}, 400 \mathrm{MHz}\right): \delta 8.38$ (ddd, J=3.8, 1.1, $\left.0.6 \mathrm{~Hz}, 1 \mathrm{H}\right), 8.05(\mathrm{dd}, \mathrm{J}=7.0,2.4 \mathrm{~Hz}, 1 \mathrm{H}), 7.98$ (d, J=8.2 Hz, 1H), 7.64-7.69 (m, 3H), 7.54 (ddd, J=8.3, 6.6, 1.4 Hz, 1H), 7.48-7.51 (m, 1H), 7.43 (ddd, J=8.5, 6.6, 1.3 Hz, 1H), 7.32 (ddd, J=5.2, 3.8, $1.3 \mathrm{~Hz}, 1 \mathrm{H}) ;{ }^{13} \mathrm{C}\left\{{ }^{1} \mathrm{H}\right\} \operatorname{NMR}\left(\mathrm{CDCl}_{3}, 100 \mathrm{MHz}\right): \delta 151.4$ (d, J=8.4 Hz), 151.2 (dd, J=256.8, $\left.20.1 \mathrm{~Hz}\right)$, 149.4 (dd, J=262.1, 21.4 Hz), 148.8 (d, J=8.3 Hz), 133.8, 131.6, $131.5(\mathrm{~m}), 131.1$ (d, J=8.0 Hz), 129.9, 129.0 (m), 128.7, 
127.7 (d, J=2.5 Hz), 127.4, 126.7, 126.2, 125.30, 125.27, 116.8 (d, J=16.7 Hz), 113.4 (d, J=12.0 Hz); anal. calcd for $\mathrm{C}_{20} \mathrm{H}_{10} \mathrm{~F}_{2} \mathrm{~N}_{2} \mathrm{~S}_{2}: \mathrm{C}, 63.14 ; \mathrm{H}, 2.65 ; \mathrm{N}, 7.36$; found: C, 63.36; H, 2.94; N, 7.02.

4-(9H-fluoren-2-yl)-7-(thiophen-2-yl)-5,6-difluoro-2,1,3-benzothiadiazole (11). The crude is purified by column chromatography using petroleum ether:toluene $=7: 3$ as eluent. Isolated product: $335 \mathrm{mg}(80 \%)$, orange powder. $\mathrm{mp}$ 196.4-197.0 ${ }^{\circ} \mathrm{C} ;{ }^{1} \mathrm{H}$ NMR $\left(\mathrm{CDCl}_{3}, 400 \mathrm{MHz}\right): \delta 8.34(\mathrm{ddd}, \mathrm{J}=3.8,1.1,0.6 \mathrm{~Hz}, 1 \mathrm{H}), 8.02(\mathrm{~m}, 1 \mathrm{H}), 7.99(\mathrm{dd}, \mathrm{J}=7.9,0.6 \mathrm{~Hz}$, 1H), 7.85-7.90 (m, 2H), $7.66(\mathrm{dd}, \mathrm{J}=5.2,1.1 \mathrm{~Hz}, 1 \mathrm{H}), 7.61(\mathrm{~d}, \mathrm{~J}=7.3 \mathrm{~Hz}, 1 \mathrm{H}), 7.45$ (t, J=7.5 Hz, $1 \mathrm{H}), 7.38(\mathrm{td}, \mathrm{J}=7.4,1.3$ $\mathrm{Hz}), 7.31$ (ddd, J=5.2, 3.9, $1.3 \mathrm{~Hz}, 1 \mathrm{H}), 4.05(\mathrm{~s}, 2 \mathrm{H}) ;{ }^{13} \mathrm{C}\left\{{ }^{1} \mathrm{H}\right\} \mathrm{NMR}\left(\mathrm{CDCl}_{3}, 100 \mathrm{MHz}\right): \delta 150.6(\mathrm{~d}, \mathrm{~J}=8.7 \mathrm{~Hz}), 150.4(\mathrm{dd}$, $\mathrm{J}=255.5,18.9 \mathrm{~Hz}), 149.8$ (dd, J=260.7, 20.3 Hz), 149.0 (d, J=8.7 Hz), 143.8, 143.4, 142.7, 141.1, 131.6 (dd, J=5.8, 3.6 Hz), 131.0 (d, J=8.7 Hz), 129.4 (d, J=2.9 Hz), 128.9 (d, J=6.5 Hz), 128.4, 127.4, 127.3, 127.1 (d, J=2.9 Hz), 126.9, 125.1, 120.3, 119.9, $118.2(\mathrm{~d}, \mathrm{~J}=14.1 \mathrm{~Hz}), 112.5$ (dd, J=12.4, $1.4 \mathrm{~Hz}), 37.1$; anal. calcd for $\mathrm{C}_{23} \mathrm{H}_{12} \mathrm{~F}_{2} \mathrm{~N}_{2} \mathrm{~S}_{2}: \mathrm{C}, 66.01 ; \mathrm{H}, 2.89 ; \mathrm{N}$, 6.69; found: C, 65.60; H, 2.67; N, 6.67.

4-(5'-hexyl-[2,2'-bithiophen]-5-yl)-7-(thiophen-2-yl)-5,6-difluoro-2,1,3-benzothiadiazole (12). The crude is purified by column chromatography using petroleum ether:toluene=6:4 as eluent. Isolated product: $201 \mathrm{mg}$ (40\%), red powder. mp 125.4-126.5; ${ }^{1} \mathrm{H} \mathrm{NMR}\left(\mathrm{CDCl}_{3}, 400 \mathrm{MHz}\right): \delta 8.28$ (dd, J=3.8, $\left.1.1 \mathrm{~Hz}, 1 \mathrm{H}\right), 8.19(\mathrm{~d}, \mathrm{~J}=4.0 \mathrm{~Hz}, 1 \mathrm{H}), 7.60$ (dd, J=5.2, $1.2 \mathrm{~Hz}$, 1H), 7.25-7.27 (m, 1H), $7.22(\mathrm{~d}, \mathrm{~J}=4.1 \mathrm{~Hz}, 1 \mathrm{H}), 7.73(\mathrm{dt}, \mathrm{J}=3.6,1.0 \mathrm{~Hz}, 1 \mathrm{H}), 2.82(\mathrm{t}, \mathrm{J}=7.6 \mathrm{~Hz}, 2 \mathrm{H}), 1.71(\mathrm{~m}, 2 \mathrm{H}), 1.31-$ $1.43(\mathrm{~m}, 6 \mathrm{H}), 0.91(\mathrm{t}, \mathrm{J}=7.1,3 \mathrm{H}) ;{ }^{13} \mathrm{C}\left\{{ }^{1} \mathrm{H}\right\} \mathrm{NMR}\left(\mathrm{CDCl}_{3}, 100 \mathrm{MHz}\right): \delta 149.9(\mathrm{dd}, \mathrm{J}=260.0,20.4 \mathrm{~Hz}), 149.6(\mathrm{dd}, \mathrm{J}=259.4$, 20.8 Hz), 148.9, 148.7, 146.6, 141.5 (t, J=2.9 Hz), 134.2, 131.9 (dd, J=5.7, 3.6 Hz), 131.7, 130.8 (t, J=3.6 Hz), 129.7 (d, $\mathrm{J}=2.2 \mathrm{~Hz}$ ), 128.8 (t, J=2.9 Hz), 127.4, 125.1, 124.2, 123.2, 111.7 (dd, J=9.5, 3.6 Hz), 111.3 (dd, J=8.9, 5.1 Hz),31.6, 31.5, 30.3, 28.8, 22.6, 14.1; anal. calcd for $\mathrm{C}_{24} \mathrm{H}_{20} \mathrm{~F}_{2} \mathrm{~N}_{2} \mathrm{~S}_{4}: \mathrm{C}, 57.34 ; \mathrm{H}, 4.01 ; \mathrm{N}, 5.57$; found: C, 56.99; $\mathrm{H}, 3.82 ; \mathrm{N}, 5.40$. Methyl 2-(2-(thiophen-2-yl)thiophen-3-yl)acetate (13). Methyl 2-(2-bromothiophen-3-yl)acetate (0.570 g, $2.42 \mathrm{mmol}), 2-$ thienylboronic acid $(0.450 \mathrm{mg}, 3.52 \mathrm{mmol})$ and $\mathrm{Pd}(\mathrm{dtbpf}) \mathrm{Cl}_{2}(29 \mathrm{mg}, 0.044 \mathrm{mmol})$ were suspended in $2 \mathrm{~mL}$ of $2 \mathrm{wt} \%$ (Kolliphor/Span 80 7:3) dispersion and stirred until complete homogenization. NEt3 (0.608 g, 6.01 mmol) was added, observing darkening and spontaneous raise in the temperature from $25^{\circ} \mathrm{C}$ to $40{ }^{\circ} \mathrm{C}$. After $2 \mathrm{~h}$ the GC-MS inspection of the reaction mixture indicated complete conversion of the bromide. Mixture was diluted with $10 \mathrm{~mL}$ of AcOEt and directly filtered through a pad of silica affording, after evaporation of the solvent, the title compound as a colorless oil ( $0.560 \mathrm{~g}$, $2.35 \mathrm{mmol}, 98 \%) .{ }^{1} \mathrm{H}$ NMR $\left(\mathrm{CDCl}_{3}, 400 \mathrm{MHz}\right): \delta 7.34(\mathrm{dd}, \mathrm{J}=5.2,1.2 \mathrm{~Hz}, 1 \mathrm{H}), 7.24$ (d, J=5.2 Hz, $\left.1 \mathrm{H}\right), 7.18(\mathrm{dd}, \mathrm{J}=3.6$, $1.2 \mathrm{~Hz}, 1 \mathrm{H}), 7.08(\mathrm{dd}, \mathrm{J}=5.2,3.6 \mathrm{~Hz}, 1 \mathrm{H}), 7.05(\mathrm{~d}, \mathrm{~J}=5.2 \mathrm{~Hz}, 1 \mathrm{H}), 3.77(\mathrm{~s}, 2 \mathrm{H}), 3.72(\mathrm{~s}, 3 \mathrm{H}) ;{ }^{13} \mathrm{C}\left\{{ }^{1} \mathrm{H}\right\} \mathrm{NMR}(\mathrm{CDCl}, 100$ $M H z): \delta 171.4,135.0,133.3,130.2,130.1,127.7,126.9,126.2,124.5,52.1,34.6$.

9-phenylanthracene (14). Phenylboronic acid (0.763 g, $6.25 \mathrm{mmol})$, 9-bromoanthracene (1.289 g, $5.00 \mathrm{mmol})$ and $\mathrm{Pd}(\mathrm{dtbpf}) \mathrm{Cl}_{2}(65.32 \mathrm{mg}, 0.100 \mathrm{mmol})$ are placed in a round bottom flask. A 2 wt\% solution of a 7:3 Kolliphor EL/Span 80 mixture is added under stirring $(5 \mathrm{~mL})$ and mixture is kept under vigorous stirring till complete homogenization. NEt 3 $(1.269 \mathrm{~g}, 12.5 \mathrm{mmol})$ is added observing darkening of the emulsion and gradual raise in the temperature from 25 to 55 ${ }^{\circ} \mathrm{C}$. The reaction is monitored by GC-MS and quenched after $30 \mathrm{~min}$, having observed complete conversion of the starting bromide. The suspension is filtered through a sintered glass filter to give an off white precipitate and a brown 
filtrate. The precipitate is crystallized from acetic acid to give the pure title compound as a bright white solid (1.246 $\mathrm{g}$, $4.80 \mathrm{mmol}, 98 \%)$. The filtrate is recycled for the subsequent run, thus fresh aliquots of phenylboronic acid $(0.763 \mathrm{~g}, 6.25$ mmol), 9-bromoanthracene (1.286 g, $5.00 \mathrm{mmol})$ and NEt3 $(1.265 \mathrm{~g}, 12.5 \mathrm{mmol})$ are added and reaction monitored by GC-MS. In the second run reaction took $2 \mathrm{~h}$ to achieve complete conversion. Work up was performed analogously to the first run ( $98 \%$ of crystallized product). In the third run, the reaction time was $4 \mathrm{~h}$ with $97 \%$ of product isolated after crystallization. In the fourth and final run the reaction took $10 \mathrm{~h}$ to give, after standard purification, the product in $94 \%$ yield. ${ }^{1} \mathrm{H} \mathrm{NMR}\left(\mathrm{CDCl}_{3}, 400 \mathrm{MHz}\right): \delta 8.50(\mathrm{~s}, 1 \mathrm{H}), 8.05(\mathrm{~d}, \mathrm{~J}=8.0 \mathrm{~Hz}, 2 \mathrm{H}), 7.67(\mathrm{~d}, \mathrm{~J}=8.9 \mathrm{~Hz}, 2 \mathrm{H}), 7.51-7.60$ (m, 3H), 7.43$7.48(\mathrm{~m}, 4 \mathrm{H}), 7.35(\mathrm{ddd}, \mathrm{J}=8.9,6.5,1.3 \mathrm{~Hz}, 2 \mathrm{H}) ;{ }^{13} \mathrm{C}\left\{{ }^{1} \mathrm{H}\right\} \mathrm{NMR}\left(\mathrm{CDCl}_{3}, 100 \mathrm{MHz}\right): \delta 138.8,137.0,131.4,131.2,130.2$, $128.4,128.3,127.4,126.8,126.5,125.3,125.1$. See $^{58}$ for a comparison.

\section{Theoretical details.}

All ab initio simulations based on density functional theory (DFT) have been performed by using the ORCA suite of programs $^{52}$ in a localized-basis-set framework. In detail, the Kohn-Sham orbitals have been expanded on a def2-TZVPP Gaussian type basis set. 59,60 The corresponding def2/J basis has been also used as an auxiliary basis set for Coulomb fitting in a resolution-of-identity/chain-of-spheres (RIJCOSX) framework. ${ }^{61}$ Molecular geometries have been fully optimized and their properties investigated by using the B3LYP functional. ${ }^{62}$ In order to simulate molecular properties inside and outside the micellar environment, the SMD continuum solvation model has been used to solvate the investigated molecules in toluene and water, respectively. ${ }^{63,64}$

\section{ASSOCIATED CONTENT}

Literature analysis on the relevance of DTBT, GC-MS traces for all reactions described in Table 1-4, UV-Vis and emission spectra for all new derivatives, copy of the ${ }^{1} \mathrm{H}$ and ${ }^{13} \mathrm{C}$ spectra for all derivatives, details on the computational analysis, DLS analysis of surfactant solutions, estimates of the E-factor for the literature and original procedures.

\section{AUTHOR INFORMATION}

\section{Corresponding Author.}

E-mail: luca.beverina@unimib.it

\section{Notes.}

There are no conflicts of interest to declare.

\section{ACKNOWLEDGEMENTS}


Financial support from the Italian Ministry of University and Research (MIUR) through grant "Dipartimenti di Eccellenza2017 Materials For Energy" is gratefully acknowledged.

\section{REFERENCES}

(1) Zhang, X.; Bäuerle, P.; Aida, T.; Skabara, P.; Kagan, C. Organic Electronics for a Better Tomorrow : Innovation, Accessibility, Sustainability. A White Paper from the Chemical Sciences and Society Summit (CS3). 2012.

(2) Po, R.; Bernardi, A.; Calabrese, A.; Carbonera, C.; Corso, G.; Pellegrino, A. From Lab to Fab: How Must the Polymer Solar Cell Materials Design Change? - an Industrial Perspective. Energy Environ. Sci. 2014, 7 (3), 925.

(3) Po, R.; Roncali, J. Beyond Efficiency: Scalability of Molecular Donor Materials for Organic Photovoltaics. J. Mater. Chem. C 2016, 4 (17), 3677-3685.

(4) Po, R.; Bianchi, G.; Carbonera, C.; Pellegrino, A. "All That Glisters Is Not Gold": An Analysis of the Synthetic Complexity of Efficient Polymer Donors for Polymer Solar Cells. Macromolecules 2015, 48 (3), 453-461.

(5) Bianchi, G.; Po, R.; Sassi, M.; Beverina, L.; Chiaberge, S.; Spera, S.; Cominetti, A. Synthesis of Dithienocyclohexanones (DTCHs) as a Family of Building Blocks for m-Conjugated Compounds in Organic Electronics. ACS Omega 2017, 2 (8), 4347-4355.

(6) You, J.; Dou, L.; Yoshimura, K.; Kato, T.; Ohya, K.; Moriarty, T.; Emery, K.; Chen, C. C.; Gao, J.; Li, G.; et al. A Polymer Tandem Solar Cell with 10.6\% Power Conversion Efficiency. Nat. Commun. 2013, 4, 1410-1446. Holliday, S.; Ashraf, R. S.; Wadsworth, A.; Baran, D.; Yousaf, S. A.; Nielsen, C. B.; Tan, C. H.; Dimitrov, S. D.; Shang, Z.; Gasparini, N.; et al. High-Efficiency and Air-Stable P3HT-Based Polymer Solar Cells with a New Non-Fullerene Acceptor. Nat. Commun. 2016, 7, 1-11.

(8) Uddin, M. A.; Lee, T. H.; Xu, S.; Park, S. Y.; Kim, T.; Song, S.; Nguyen, T. L.; Ko, S. J.; Hwang, S.; Kim, J. Y.; et al. Interplay of Intramolecular Noncovalent Coulomb Interactions for Semicrystalline Photovoltaic Polymers. Chem. Mater. 2015, 27 (17), 5997-6007.

(9) Li, W.; Deng, W.; Wu, K.; Xie, G.; Yang, C.; Wu, H.; Cao, Y. The End-Capped Group Effect on Dithienosilole Trimer Based Small Molecules for Efficient Organic Photovoltaics. J. Mater. Chem. C 2016, 4 (10), 1972-1978.

(10) Fan, B.; Sun, C.; Jiang, X. F.; Zhang, G.; Chen, Z.; Ying, L.; Huang, F.; Cao, Y. Improved Morphology and Efficiency of Polymer Solar Cells by Processing Donor-Acceptor Copolymer Additives. Adv. Funct. Mater. 2016, 26 (35), $6479-6488$.

(11) Heuvel, R.; van Franeker, J. J.; Janssen, R. A. J. Energy Level Tuning of Poly(Phenylene-AltDithienobenzothiadiazole)s for Low Photon Energy Loss Solar Cells. Macromol. Chem. Phys. 2017, 218 (5), 1600502.

(12) Li, G.; Kang, C.; Gong, X.; Zhang, J.; Li, C.; Chen, Y.; Dong, H.; Hu, W.; Li, F.; Bo, Z. 5-Alkyloxy-6-Fluorobenzo[ $c$ ][1,2,5]Thiadiazole- and Silafluorene-Based D-A Alternating Conjugated Polymers: Synthesis and Application in Polymer Photovoltaic Cells. Macromolecules 2014, 47 (14), 4645-4652.

(13) Zhang, J.; Chen, W.; Rojas, A. J.; Jucov, E. V.; Timofeeva, T. V.; Parker, T. C.; Barlow, S.; Marder, S. R. Controllable Direct Arylation: Fast Route to Symmetrical and Unsymmetrical 4,7-Diaryl-5,6-Difluoro-2,1,3-Benzothiadiazole 
Derivatives for Organic Optoelectronic Materials. J. Am. Chem. Soc. 2013, 135 (44), 16376-16379.

(14) Cox, P. A.; Leach, A. G.; Campbell, A. D.; Lloyd-Jones, G. C. Protodeboronation of Heteroaromatic, Vinyl, and Cyclopropyl Boronic Acids: PH-Rate Profiles, Autocatalysis, and Disproportionation. J. Am. Chem. Soc. 2016, 138 (29), 9145-9157.

(15) Lipshutz, B. H.; Gallou, F.; Handa, S. Evolution of Solvents in Organic Chemistry. ACS Sustain. Chem. Eng. 2016, 4 (11), 5838-5849.

(16) Kitanosono, T.; Masuda, K.; Xu, P.; Kobayashi, S. Catalytic Organic Reactions in Water toward Sustainable Society. Chem. Rev. 2018, 118 (2), 679-746.

(17) Romney, D. K.; Arnold, F. H.; Lipshutz, B. H.; Li, C. J. Chemistry Takes a Bath: Reactions in Aqueous Media. J. Org. Chem. 2018, 83 (14), 7319-7322.

(18) Ghorai, S.; Lipshutz, B. H. Transition-Metal-Catalyzed Cross-Couplings Going Green: In Water at Room Temperature. Aldrichimica Acta 2008, 41 (3), 59-72.

(19) Dwars, T.; Paetzold, E.; Oehme, G. Reactions in Micellar Systems. Angew. Chemie - Int. Ed. 2005, 44 (44), 7174-7199.

(20) La Sorella, G.; Strukul, G.; Scarso, A. Recent Advances in Catalysis in Micellar Media. Green Chem. 2015, 17 (2), 644683.

(21) Lee, M.; Jang, C. J.; Ryu, J. H. Supramolecular Reactor from Self-Assembly of Rod-Coil Molecule in Aqueous Environment. J. Am. Chem. Soc. 2004, 126 (26), 8082-8083.

(22) Lipshutz, B. H.; Ghorai, S.; Cortes-Clerget, M. The Hydrophobic Effect Applied to Organic Synthesis: Recent Synthetic Chemistry “in Water." Chem. - A Eur. J. 2018, 24 (26), 6672-6695.

(23) Lipshutz, B. H. When Does Organic Chemistry Follow Nature's Lead and "Make the Switch"? J. Org. Chem. 2017, 82 (6), 2806-2816.

(24) Clavé, G.; Pelissier, F.; Campidelli, S.; Grison, C. Ecocatalyzed Suzuki Cross Coupling of Heteroaryl Compounds. Green Chem. 2017, 19 (17), 4093-4103.

(25) Bu, M. J.; Cai, C.; Gallou, F.; Lipshutz, B. H. PQS-Enabled Visible-Light Iridium Photoredox Catalysis in Water at Room Temperature. Green Chem. 2018, 20 (6), 1233-1237.

(26) Handa, S.; Smith, J. D.; Zhang, Y.; Takale, B. S.; Gallou, F.; Lipshutz, B. H. Sustainable HandaPhos-Ppm Palladium Technology for Copper-Free Sonogashira Couplings in Water under Mild Conditions. Org. Lett. 2018, 20 (3), $542-545$.

(27) Handa, S.; Smith, J. D.; Hageman, M. S.; Gonzalez, M.; Lipshutz, B. H. Synergistic and Selective Copper/Ppm PdCatalyzed Suzuki-Miyaura Couplings: In Water, Mild Conditions, with Recycling. ACS Catal. 2016, 6 (12).

(28) Yadav, M. R.; Nagaoka, M.; Kashihara, M.; Zhong, R. L.; Miyazaki, T.; Sakaki, S.; Nakao, Y. The Suzuki-Miyaura Coupling of Nitroarenes. J. Am. Chem. Soc. 2017, 139 (28), 9423-9426.

(29) Handa, S.; Andersson, M. P.; Gallou, F.; Reilly, J.; Lipshutz, B. H. HandaPhos: A General Ligand Enabling Sustainable Ppm Levels of Palladium-Catalyzed Cross-Couplings in Water at Room Temperature. Angew. Chemie - Int. Ed. 2016, 55 (16), 4914-4918. 
(30) Lipshutz, B. H.; Abela, A. R. Micellar Catalysis of Suzuki - Miyaura Cross-Couplings with Heteroaromatics in Water. Org. Lett. 2008, 10 (23), 5329-5332.

(31) Klumphu, P.; Desfeux, C.; Zhang, Y.; Handa, S.; Gallou, F.; Lipshutz, B. H. Micellar Catalysis-Enabled Sustainable Ppm Au-Catalyzed Reactions in Water at Room Temperature. Chem. Sci. 2017, 8 (9), 6354-6358.

(32) Brals, J.; Smith, J. D.; Ibrahim, F.; Gallou, F.; Handa, S. Micelle-Enabled Palladium Catalysis for Convenient Sp ${ }^{2}-S p{ }^{3}$ Coupling of Nitroalkanes with Aryl Bromides in Water Under Mild Conditions. ACS Catal. 2017, 7 (10), 7245-7250.

(33) Handa, S.; Slack, E. D.; Lipshutz, B. H. Nanonickel-Catalyzed Suzuki-Miyaura Cross-Couplings in Water. Angew. Chemie 2015, 127 (41), 12162-12166.

(34) Isley, N. A.; Linstadt, R. T. H.; Kelly, S. M.; Gallou, F.; Lipshutz, B. H. Nucleophilic Aromatic Substitution Reactions in Water Enabled by Micellar Catalysis. Org. Lett. 2015, 17 (19), 4734-4737.

(35) Lipshutz, B. H.; Chung, D. W.; Rich, B. Sonogashira Couplings of Aryl Bromides : Room Temperature , Water Only , No Copper. Org. Lett. 2008, 10 (17), 3793-3796.

(36) Handa, S.; Wang, Y.; Gallou, F.; Lipshutz, B. H. Sustainable Fe-ppm Pd Nanoparticle Catalysis of Suzuki-Miyaura Cross-Couplings in Water. Science (80-. ). 2015, 349 (6252), 1087-1092.

(37) Kondo, K.; Klosterman, J. K.; Yoshizawa, M. Aromatic Micelles as a New Class of Aqueous Molecular Flasks. Chem. - A Eur. J. 2017, 23 (66), 16710-16721.

(38) Vaghi, L.; Sanzone, A.; Sassi, M.; Pagani, S.; Papagni, A.; Beverina, L. Synthesis of Fluorinated Acridines via Sequential Micellar Buchwald-Hartwig Amination/Cyclization of Aryl Bromides. Synth. 2018, 50 (8), 1621-1628.

(39) Rooney, M.; Mattiello, S.; Stara, R.; Sanzone, A.; Brazzo, P.; Sassi, M.; Beverina, L. Suzuki-Miyaura Cross-Coupling of Latent Pigments in Water/Toluene Emulsion under Aerobic Atmosphere. Dye. Pigment. 2018, 149, 893-901.

(40) Mattiello, S.; Rooney, M.; Sanzone, A.; Brazzo, P.; Sassi, M.; Beverina, L. Suzuki-Miyaura Micellar Cross-Coupling in Water, at Room Temperature, and under Aerobic Atmosphere. Org. Lett. 2017, 19 (3), 654-657.

(41) Lipshutz, B. H.; Ghorai, S.; Abela, A. R.; Moser, R.; Nishikata, T.; Duplais, C.; Krasovskiy, A.; Gaston, R. D.; Gadwood, R. C. TPGS-750-M: A Second-Generation Amphiphile for Metal-Catalyzed Cross-Couplings in Water at Room Temperature. J. Org. Chem. 2011, 76 (11), 4379-4391.

(42) Brocklehurst, C. E.; Gallou, F.; Hartwieg, J. C. D.; Palmieri, M.; Rufle, D. Microtiter Plate (MTP) Reaction Screening and Optimization of Surfactant Chemistry: Examples of Suzuki-Miyaura and Buchwald-Hartwig Cross-Couplings in Water. Org. Process Res. Dev. 2018, 22, 1453-1457.

(43) Gabriel, C. M.; Lee, N. R.; Bigorne, F.; Klumphu, P.; Parmentier, M.; Gallou, F.; Lipshutz, B. H. Effects of Co-Solvents on Reactions Run under Micellar Catalysis Conditions. Org. Lett. 2017, 19 (1), 194-197.

(44) Guo, P.; Zhang, H.; Zhou, J.; Gallou, F.; Parmentier, M.; Wang, H. Micelle-Enabled Suzuki-Miyaura Cross-Coupling of Heteroaryl Boronate Esters. J. Org. Chem. 2018, 83 (14), 7523-7527.

(45) Ghorai, S.; Lipshutz, B. H. "Designer"-Surfactant-Enabled Cross-Couplings in Water at Room Temperature. Aldrichimica Acta 2012, 45 (1), 3-16. 
(46) Klumphu, P.; Lipshutz, B. H. "Nok": A Phytosterol-Based Amphiphile Enabling Transition-Metal-Catalyzed Couplings in Water at Room Temperature. J. Org. Chem. 2014, 79 (3), 888-900.

(47) Rühling, A.; Galla, H.-J.; Glorius, F. A Remarkably Simple Hybrid Surfactant-NHC Ligand, Its Gold-Complex, and Application in Micellar Catalysis. Chemistry 2015, 21 (35), 12291-12294.

(48) Andersson, M. P.; Gallou, F.; Klumphu, P.; Takale, B. S.; Lipshutz, B. H. Structure of Nanoparticles Derived from Designer Surfactant TPGS-750-M in Water, As Used in Organic Synthesis. Chem. - A Eur. J. 2018, 24 (26), $6778-6786$.

(49) Mollet, H.; Grubenmann, A. Formulation Technology; John Wiley \& Sons, 2008.

(50) Colacot, T. J.; Shea, H. A. Cp2Fe(PR2)2PdCl2 (R = i-Pr, t-Bu) Complexes as Air-Stable Catalysts for Challenging Suzuki Coupling Reactions. Org. Lett. 2004, 6 (21), 3731-3734.

(51) Parmentier, M.; Gabriel, C. M.; Guo, P.; Isley, N. A.; Zhou, J.; Gallou, F. Switching from Organic Solvents to Water at an Industrial Scale. Curr. Opin. Green Sustain. Chem. 2017, 7, 13-17.

(52) Neese, F. The ORCA Program System. WIREs Comput. Mol. Sci. 2012, 2 (1), 73-78.

(53) Nitti, A.; Bianchi, G.; Po, R.; Swager, T. M.; Pasini, D. Domino Direct Arylation and Cross-Aldol for Rapid Construction of Extended Polycyclic m-Scaffolds. J. Am. Chem. Soc. 2017, 139 (26), 8788-8791.

(54) Neto, B. A. D.; Carvalho, P. H. P. R.; Correa, J. R. Benzothiadiazole Derivatives as Fluorescence Imaging Probes: Beyond Classical Scaffolds. Acc. Chem. Res. 2015, 48 (6), 1560-1569.

(55) Ding, D.; Goh, C. C.; Feng, G.; Zhao, Z.; Liu, J.; Liu, R.; Tomczak, N.; Geng, J.; Tang, B. Z.; Ng, L. G.; et al. Ultrabright Organic Dots with Aggregation-Induced Emission Characteristics for Real-Time Two-Photon Intravital Vasculature Imaging. Adv. Mater. 2013, 25 (42), 6083-6088.

(56) Qin, W.; Li, K.; Feng, G.; Li, M.; Yang, Z.; Liu, B.; Tang, B. Z. Bright and Photostable Organic Fluorescent Dots with Aggregation-Induced Emission Characteristics for Noninvasive Long-Term Cell Imaging. Adv. Funct. Mater. 2014, 24, $635-643$.

(57) Nielsen, C. B.; White, A. J. P.; McCulloch, I. Effect of Fluorination of 2,1,3-Benzothiadiazole. J. Org. Chem. 2015, 80 (10), 5045-5048.

(58) Fujita, T.; Takahashi, I.; Hayashi, M.; Wang, J.; Fuchibe, K.; Ichikawa, J. Facile Synthesis of Polycyclic Aromatic Hydrocarbons: Brønsted Acid Catalyzed Dehydrative Cycloaromatization of Carbonyl Compounds in 1,1,1,3,3,3Hexafluoropropan-2-OI. European J. Org. Chem. 2017, 2017 (2), 262-265.

(59) Schäfer, A.; Horn, H.; Ahlrichs, R. Fully Optimized Contracted Gaussian Basis Sets for Atoms Li to Kr. J. Chem. Phys. 1992, $97(4), 2571-2577$.

(60) Weigend, F.; Ahlrichs, R. Balanced Basis Sets of Split Valence, Triple Zeta Valence and Quadruple Zeta Valence Quality for H to Rn: Design and Assessment of Accuracy. Phys. Chem. Chem. Phys. 2005, 7 (18), 3297-3305.

(61) Weigend, F. Accurate Coulomb-Fitting Basis Sets for H to Rn. Phys. Chem. Chem. Phys. 2006, 8 (9), $1057-1065$.

(62) Becke, A. D. Density-Functional Thermochemistry. III. The Role of Exact Exchange. J. Chem. Phys. 1993, 98 (7), 56485652. 
(63) Marenich, A. V; Cramer, C. J.; Truhlar, D. G. Unviersal Solvation Modle Based on Solute Electron Density and a Contiuum Model of the Solvent Defind by the Bulk Dielectric Constant and Atomic Surface Tensions. J. Phys. Chem. B. 2009, 113, 6378-6396.

(64) Barone, V.; Cossi, M. Quantum Calculation of Molecular Energies and Energy Gradients in Solution by a Conductor Solvent Model. J. Phys. Chem. A 1998, 102 (11), 1995-2001. 